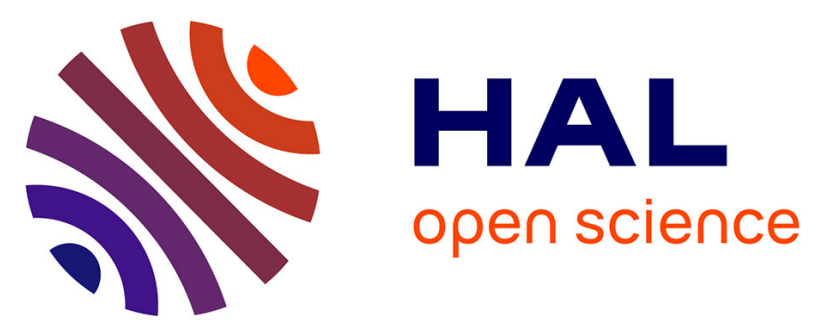

\title{
Synthesis of 3D dendritic gold nanostructures assisted by a templated growth process: Application at the detection of traces of molecules
}

Pierre Bauer, Karine Mougin, Delphine Faye, A. Buch, Pierre Ponthiaux, Vincent Vignal

\section{To cite this version:}

Pierre Bauer, Karine Mougin, Delphine Faye, A. Buch, Pierre Ponthiaux, et al.. Synthesis of 3D dendritic gold nanostructures assisted by a templated growth process: Application at the detection of traces of molecules. Langmuir, 2020, 36 (37), pp.11015-11027. 10.1021/acs.langmuir.0c01857 . hal-03024511

\section{HAL Id: hal-03024511 \\ https://hal.science/hal-03024511}

Submitted on 25 Nov 2020

HAL is a multi-disciplinary open access archive for the deposit and dissemination of scientific research documents, whether they are published or not. The documents may come from teaching and research institutions in France or abroad, or from public or private research centers.
L'archive ouverte pluridisciplinaire HAL, est destinée au dépôt et à la diffusion de documents scientifiques de niveau recherche, publiés ou non, émanant des établissements d'enseignement et de recherche français ou étrangers, des laboratoires publics ou privés. 


\title{
Synthesis of 3D Dendritic Gold Nanostructures Assisted by a Templated Growth Process: Application to the Detection of Traces of Molecules
}

\author{
Pierre Bauer,* Karine Mougin, Delphine Faye, Arnaud Buch, Pierre Ponthiaux, and Vincent Vignal
}

Cite This: https://dx.doi.org/10.1021/acs.langmuir.0c01857

Read Online

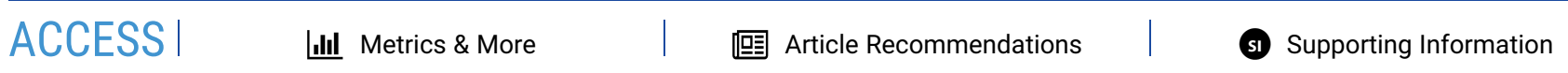
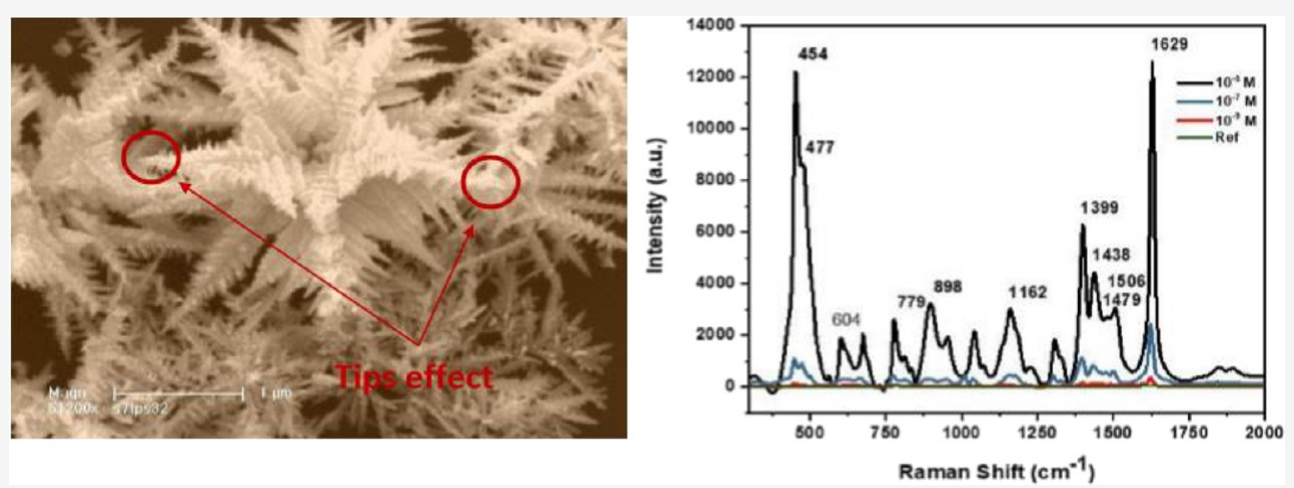

ABSTRACT: Complex architectures like 3D gold dendritic nanostructures were synthesized by an in situ templated growth method using a thin film of a block copolymer [polystyrene-b-poly(4-vinylpyridine)] deposited onto silicon substrates. The overall study has demonstrated the strong link between the morphology, size, and distribution of the structures and the synthetic physicochemical parameters, such as $\mathrm{pH}$, reaction temperature, concentration, and nature of reactants. A nonequilibirum state of the medium has been required to create a fractal growth of the gold structures onto a prepatterned gold-seeded surface and has led to a better control of the structures' surface coverage rate. Those as-prepared nanodendrites have also exhibited high electrocatalytic activity toward a significant enhancement factor, as well as important sensitivity, thanks to tip effects. The electrochemical experiment results have demonstrated efficient adsorption and quantification of very low traces of specific molecules like glutathione or hexadecanethiol.

\section{INTRODUCTION}

Noble metal nanoparticles (NPs) have been extensively studied due to their fascinating optical, electronic, or catalytic properties and their promising applications in photoluminescence, ${ }^{1}$ superhydrophobic surfaces, ${ }^{2}$ sensors/biosensors, ${ }^{3-5}$ catalysis, ${ }^{6}$ or surface enhanced raman scattering spectroscopy (SERS). ${ }^{7-9}$ Indeed, the long-range and large-scale arrangement of metal NPs represents an important issue in the development of nanostructured materials. Especially gold nanoparticles (AuNPs) have attracted a great deal of interest. Due to their high stability (which is an advantage compared to other metals), AuNPs possess unique properties, such as excellent electrical and heat conductivity and strong adsorption in the visible and near-infrared wavelength region $(380-750 \mathrm{~nm})$.

Great efforts have been devoted to synthesize gold nanomaterials with novel morphologies. The control of the shape, size, and distribution of those particular structures has become a major challenge, since it considerably influences their intrinsic properties. Among various shapes, such as rods, ${ }^{10}$ prisms, ${ }^{11}$ cubes, ${ }^{12}$ stars, ${ }^{13,14}$ or dendrites, ${ }^{15,16}$ dendritic nanostructures have attracted much attention because of their high effective surface-to-volume ratio, high sensitivity, and special texture with sharp tips and nanoscale junctions. Because of the highly symmetric face-centered cubic (fcc) crystal structure of $\mathrm{Au}$, difficulties appeared in forming well-defined dendritic nanostructures with a homogeneous distribution. A nonequilibrium state is usually required to adjust reaction parameters (such as solvent, reactant concentration, temperature, $\mathrm{pH}$ ) and to select the growth method. ${ }^{17}$

Various methods have been developed to fabricate those specific structures, such as electrodeposition, ${ }^{18,19}$ hydrothermal reduction, ${ }^{20}$ seed-mediated growth, ${ }^{21,22}$ or the wet chemical way. ${ }^{23,24} \mathrm{Lv}$ and co-workers have reported several facile and controlled electrochemical routes to prepare three-dimensional hierarchical dendritic gold nanostructures with different amino-

Received: June 23, 2020

Revised: August 31, 2020

Published: August 31, 2020 
capping agents. ${ }^{25,26}$ However, the seed-mediated growth can offer an alternative process to improve the surface coverage rate of nanostructures relative to the Frens method. ${ }^{27}$ In order to control the nucleation density in $2 \mathrm{D}$ arrays, Park et al. have worked on the fabrication of a nanoporous template made of a diblock copolymer such as polystyrene- $b$-poly(2-vinylpyridine) (PS-b-P4VP). ${ }^{28,29}$ This method has allowed an optimization of the distribution of gold dendritic nanocrystals onto the surface. However, despite all these efforts to improve the quality and variability in the synthesis of flower-like structures, the detailed mechanism through which they evolve from spherical seeds has not been yet completely understood.

A significant amount of research has been devoted to the development of effective analytical protocols for measuring traces of molecules. A wide range of detection strategies is now available, such as fluorescence, ${ }^{30}$ mass spectroscopy, or electrochemistry. ${ }^{31}$ Among all, electrochemical methods propose certain advantages, such as simplicity, rapidity, lower cost, and higher limit of detection. The groups of Wang and Coussot have reported the sensitive quantification of aminoacids and glucose using glassy carbon electrodes modified with multiwalled carbon nanotubes and copper microparticles. ${ }^{32,33}$ Dehdari Vais et al. have recorded cyclic voltammograms of $\mathrm{Au}$ pyramidal electrodes in phosphate-buffered saline (PBS) solution in the absence and presence of azathioprine. ${ }^{34}$ More recently, Liu and co-workers have worked on the development of an electrochemical DNA biosensor via an electrode modified with dendritic gold nanostructures to gain ultrasensitivity (fM) and a dynamic detection range (from $1 \mathrm{fM}$ to $1 \mathrm{nM}$ ). ${ }^{35}$

In this work, we describe the development of an electrochemical and optical sensor for the detection and quantification of traces of organic molecules. The active platform has been structured with gold flower-like crystals (AuNFs) grown onto a nanopatterned stainless steel substrate. Relevant and effective reaction conditions have been discussed to obtain well-defined gold dendritic structures with controlled symmetries. Scanning electron microscopy (SEM) and X-ray diffraction (XRD) have allowed studying the shape, size, coverage rate, and crystallography of the metallic nanostructures. Then, quantification of adsorbed probe molecules (glutathione and hexadecanethiol) on gold structures has been carried out by local and global electrochemistry methods. Results were encouraging, showing the possibility to both discriminate and quantify adsorbed molecules at very low concentrations. Correlated localized surface plasmon resonance properties of the sensor device have also been investigated, showing its high sensitivity. Overall, the proposed process itself represents a highly interesting and promising route for producing a sensitive sensor using a very simple method, and more importantly, it will also contribute to a better understanding of the growth mechanism of anisotropic metal nanoparticles.

\section{MATERIALS AND METHODS}

Materials. Tetrachloroauric acid trihydrate $\left(\mathrm{HAuCl}_{4} \cdot 3 \mathrm{H}_{2} \mathrm{O}\right.$, $\geq 99.9 \%$ ), cethyl trimethylammonium bromide (CTAB, $\geq 99.9 \%$ ), hydrazine hydrate $\left(\mathrm{N}_{2} \mathrm{H}_{4}, 50-60 \%\right)$, and glutathione ( $\left.\mathrm{GSH}, \geq 99 \%\right)$ were all purchased from Sigma-Aldrich. Hydroxylamine hydrochloric $\left(\mathrm{NH}_{2} \mathrm{OH}, \geq 99 \%\right.$ trace metal basis) and methylene blue ( $\left.\mathrm{MB}, \geq 99 \%\right)$ were purchased from Fluka. Polystyrene-b-poly(4-vinylpyridine) $\left(\mathrm{PS}_{40000}-b-\mathrm{P} 4 \mathrm{VP}_{5600}\right.$ with $\left.M_{\mathrm{w}} / M_{\mathrm{n}}=1.10\right)$ and $2-(4-$ hydroxyphenylazo)benzoic acid (HABA, $\geq 98 \%$ ) were purchased from Interchim. Coomassie brilliant blue (CBB, $\geq 99 \%)$ was supplied by Cap Alpha. Buffer T1 (5\% ice-cold acetic acid, 10\% methanol, 85\% Milli-Q water), buffer T2 (0.25 M aqueous sodium carbonate $50 \%$ diluted in methanol, $\mathrm{pH} 11.25$ ), and buffer $\mathrm{T} 2 \mathrm{HCl}$ ( $92 \%$ of buffer $\mathrm{T} 2$ with $8 \%$ of $3 \mathrm{~N} \mathrm{HCl}$ ) were prepared in the lab. Water was purified using a Milli-Q system.

Template Fabrication. The multistep fabrication of nanostructured films started by a mechanical polish (Mecapol P320 Presi Device) of 304L stainless steel plates $\left(10 \times 15 \times 1 \mathrm{~mm}^{3}\right)$ to control their roughness $\left(S_{\mathrm{a}}=0.34\right)$. Samples were finally washed twice in dichloromethane. Then, thin films of the diblock copolymer PS- $b$-P4VP mixed with $\mathrm{HABA}$ into chloroform were deposited by dip-coating over a large area onto cleaned stainless steel surfaces. The thickness of the dip-coated film on the surface was evaluated as $45 \pm 2 \mathrm{~nm}$, measured by ellipsometry (Multiskop OPTREL). The (PS- $b$-P4VP + HABA) phase separation was then enhanced by 4 days of solvent annealing in a saturated vapor of 1,4-dioxane. HABA was then removed by dipping the substrate in a methanol bath for $5 \mathrm{~min}$, and sample was dried under a nitrogen flow. The nanoporous film sample was placed under UV light $(\lambda=254 \mathrm{~nm})$ for $30 \mathrm{~min}$ in order to strengthen the mask against hydrolysis, but also to stabilize it over the time. Argon plasma treatment was used (power, $90 \mathrm{~W}$; pressure, $1 \mathrm{mbar}$ ) during $60 \mathrm{~s}$ to burn residues of HABA or P4VP coating the bottom of the nanopores.

Synthesis of Au Dendritic Nanostructures. Samples were immersed in $5 \mathrm{~mL}$ of colloidal gold aqueous solution ( $0.001 \% \mathrm{wt})$ for $1 \mathrm{~h}$ and then reduced by a solution of hydrazine hydrate $(10 \mu \mathrm{L})$. In a typical synthesis of $\mathrm{Au}$ dendritic structures, samples (recovered with PS- $b$-P4VP and gold seeds) were immersed in $5 \mathrm{~mL}$ of $\mathrm{NH}_{2} \mathrm{OH}$ aqueous solution $(20 \mathrm{mM})$ for $45 \mathrm{~min}$ under controlled temperature and $\mathrm{pH}$. Then $50 \mu \mathrm{L}$ of $\mathrm{HAuCl}_{4}$ aqueous solution (1\% wt) was added and the solution was kept under controlled conditions without stirring for $1 \mathrm{~h}$. Samples were then washed with distilled water and dried under nitrogen flow. The obtained gold nanostructures were characterized by SEM and XRD.

Multifractal Analysis. Fractals have revolutionized the geometric description of real objects and they have been applied in various fields, like geophysics, materials sciences, ecology, and medical science. The concept of fractals enables description of complex physical objects that have irregular shapes or fragmentated structures and that can be assigned to noninteger dimensions. Although multifractals provide a powerful mathematical model for complex structures, applied sciences were more often using a single fractal dimension to describe nonEuclidean objects. ${ }^{36}$

Multifractal analysis can be used as an extension of the monofractal analysis and decomposes self-similar measures into intertwined fractal sets that are characterized by their singularity strength and fractal dimension. Multifractals can therefore be described as a superposition of homogeneous fractal objects. In multifractal analysis, the probability $\left(P_{i}\right)$ of finding the object pixel in the $i$ th box is determined by

$$
P_{i}(\varepsilon) \sim \varepsilon^{\alpha_{i}}
$$

where $\alpha_{i}$ is the Lipschitz-Hölder exponent corresponding to the density in the $i$ th box. The number of boxes $[N(\alpha)]$ where $P_{i}$ has singularity strengths between $\alpha$ and $\alpha+\mathrm{d} \alpha$ is found to scale as

$$
N(\alpha) \sim \varepsilon^{-f(\alpha)}
$$

where $f(\alpha)$ is the Hausdorff fractal dimension of the set of boxes with singularities $\alpha$. The box counting method determines the partition function $X(q, \varepsilon)$, which can be considered as the probability to find the object in the $i$ th box for different moments $q$ varying in the $[-\infty, \infty]$ interval. The partition function $(X)$ is expressed as

$$
X(q, \varepsilon)=\sum_{i=1}^{N(\varepsilon)} p_{i}^{q}(\varepsilon) \sim \varepsilon^{(q-1) D_{q}}
$$

with $D_{q}$ being the generalized dimensions corresponding to the scaling exponents for the $q$ th moment of the measure. $D_{q}$ is finally defined as

$$
D_{q}=\frac{1}{1-q} \lim _{\varepsilon \rightarrow 0} \frac{\log \sum_{i=1}^{N(\varepsilon)} p_{i}^{q}(\varepsilon)}{\log \varepsilon}
$$


Three generalized dimensions were of particular interest: $(1) D_{0}$, the capacity dimension, which describes how a multifractal system covers the observed domain; (2) $D_{1}$, the information dimension (or Shanon entropy), which characterizes the degree of disorder in a distribution; and (3) $\mathrm{D}_{2}$, the correlation dimension, which indicates the degree of clustering. Higher $D_{0}$ values indicate higher degrees of space coverage, while higher $D_{1}$ values correspond to higher disorder and lower $D_{2}$ values suggest a higher clustering level. Figure 1 depicts the general shape of a multifractal system for which $D_{2}<D_{1}<D_{0}$.

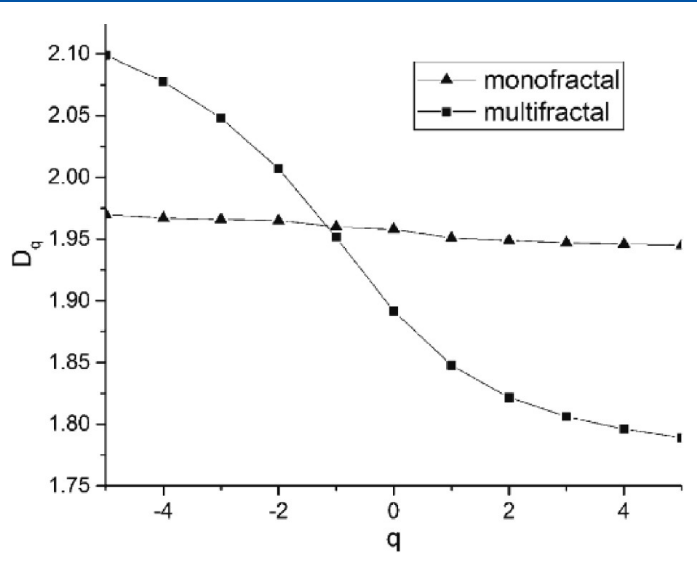

Figure 1. Generalized dimensions $D_{q}$ versus moment $q$ for a multifractal and a monofractal object.

Optical Measurements. Surface-enhanced raman scattering (SERS) spectra were acquired using a Raman spectrometer (Labram BX40 Horiba) equipped with a CCD detector with a spectral resolution of $5 \mathrm{~cm}^{-1}$. Prepatterned samples were illuminated by a linearly polarized $\mathrm{He}-\mathrm{Ne}$ source at $633 \mathrm{~nm}$ with an output power $P=50 \mathrm{~mW}$ through a $100 \times$ objective lens, which is also used to detect the backscattered light (Rayleigh and Raman signals). In such a configuration, the laser spot size has been estimated as $80 \mu \mathrm{m}^{2}$. A notch filter of optical density 6 was placed at the entrance of the spectrometer to reflect the Rayleigh signal. Each spectrum $\left(300-3000 \mathrm{~cm}^{-1}\right)$ was the average of five scans with a total acquisition time of $10 \mathrm{~s}$. The wavelength of the camera was calibrated using the Raman band of silicon (100) wafers.

The reference sample was prepared by evaporation of gold onto a stainless steel plate $(50 \mathrm{~nm})$, immersion into a $\mathrm{MB}$ aqueous solution, and then washing with distilled water and drying under atmospheric conditions. Samples were prepared by immersing the prepatterned surface with gold dendritic structures in variable concentrations (from $10^{-9}$ up to $10^{-3} \mathrm{M}$ ) of $\mathrm{MB}$ aqueous solutions. They were then washed with distilled water and dried in a desiccator. Measurements at different positions were carried out for each sample to analyze both the homogeneity of the distribution of the structures on the substrates and the reproducibility of the nanostructures' plasmon bands response.

ADECA Colorimetric Method. The amino density estimation by colorimetric assay (ADECA) colorimetric method is a process to quantify the amount of adsorbed molecules on the surface. ${ }^{37}$ This technique has to be calibrated in order to link the number of active sites on the substrates with the absorbance of adsorbed free dyes by UV spectroscopy (PerkinElmer Lambda 750). Different concentrations of CBB solutions have been prepared $(2.5,5,10,20,30,40,50$, and 60 $\mathrm{mg} / \mathrm{L}$ ) by dilution of a mother one. $\mathrm{A} 3 \mathrm{~mL}$ portion of $\mathrm{CBB}$ solution and $240 \mu \mathrm{L}$ of $\mathrm{T} 2 \mathrm{HCl}$ buffer were mixed together in disposable cuvettes $\left(12.5 \times 12.5 \times 45 \mathrm{~mm}^{3}\right)$. The curve $A=f([\mathrm{CBB}])$ can be then plotted according to Beer-Lambert's law as depicted in Figure 2.

In a $25 / 2$ proportion of $\mathrm{CBB}$ and $\mathrm{HCl}$, two forms of the dye molecule are visible in Figure $2 \mathrm{a}(\mathrm{pH}$ 8.4). The acidic form seems to absorb at 450 $\mathrm{nm}$ and the basic form at $650 \mathrm{~nm}$. As expected, a linear increase of absorbance is observable with the increase of $\mathrm{CBB}$ concentration, validating Beer-Lambert's law (Figure $2 \mathrm{~b}$ ). This fitting of the curve gives us the equation $A=0.059[\mathrm{CBB}]+0.066 \approx 0.059[\mathrm{CBB}]$ in first approximation. Hence, this system allows use of relatively low concentrations of free dye for free site detection. Then, it is possible to link the absorbance and the number of active sites by the equation

$$
N=\frac{A N_{\mathrm{a}} V}{0.059 M_{\mathrm{CBB}}}
$$

where $N$ is the number of active sites on the sample, $A$ is the maximum absorbance of the free dye, $N_{\mathrm{a}}$ is the Avogadro number, $V$ is the volume of dye released $(3 \mathrm{~mL}+240 \mu \mathrm{L}), M_{\mathrm{CBB}}$ is the molecular weight of the dye $(M=855.02 \mathrm{~g} / \mathrm{mol})$, and 0.059 is the slope of the Beer-Lambert's curve.

A first step of conditioning was performed by immersing samples into $4 \mathrm{~mL}$ of colorized buffer T1 during $10 \mathrm{~min}$. Then, staining in $2 \mathrm{~mL}$ of $\mathrm{CBB}$ coloration solution was realized during an appropriate time. Samples were washed three times in $\mathrm{T} 1$ buffer and distilled water during 10 min. Finally, after this step of washing, samples were immersed in 3 $\mathrm{mL}$ of decolorized buffer T2 for $30 \mathrm{~min}$. Spectroscopic measurements have been recorded with $3 \mathrm{~mL}$ of solution and an appropriate amount $(240 \mu \mathrm{L})$ of reading buffer $\mathrm{T} 2 \mathrm{HCl}$.

Local and Global Electrochemical Experiments. The local and global electrochemical measurements were performed with a potentiostat Biologic SP200.
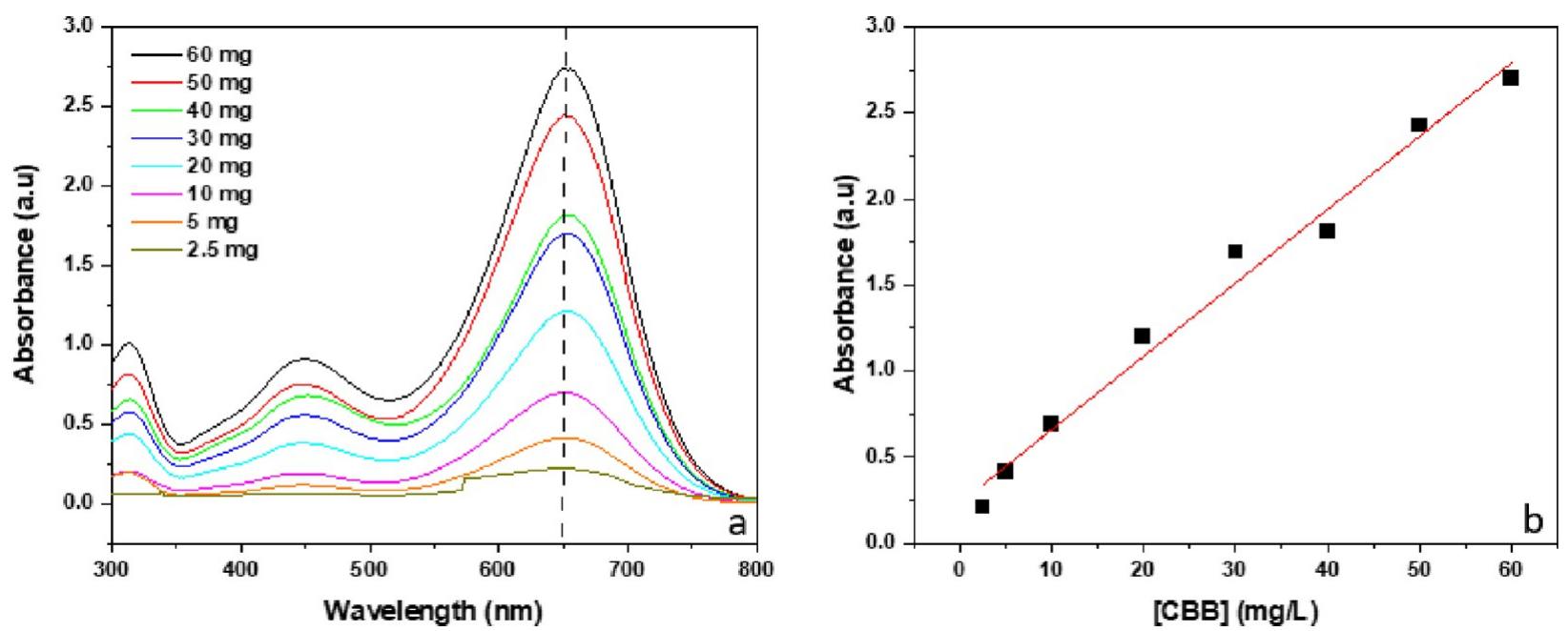

Figure 2. (a) UV-visible spectra of a mixed solution of $\mathrm{CBB}$ and $\mathrm{T} 2 \mathrm{HCl}$ buffer $(25 / 2)$ with different amounts of $\mathrm{CBB}$ and (b) plot of the maximum absorbance of $\mathrm{CBB}$ at $650 \mathrm{~nm}$ vs $\mathrm{CBB}$ concentration according to Beer-Lambert law (i.e., calibration curve). 


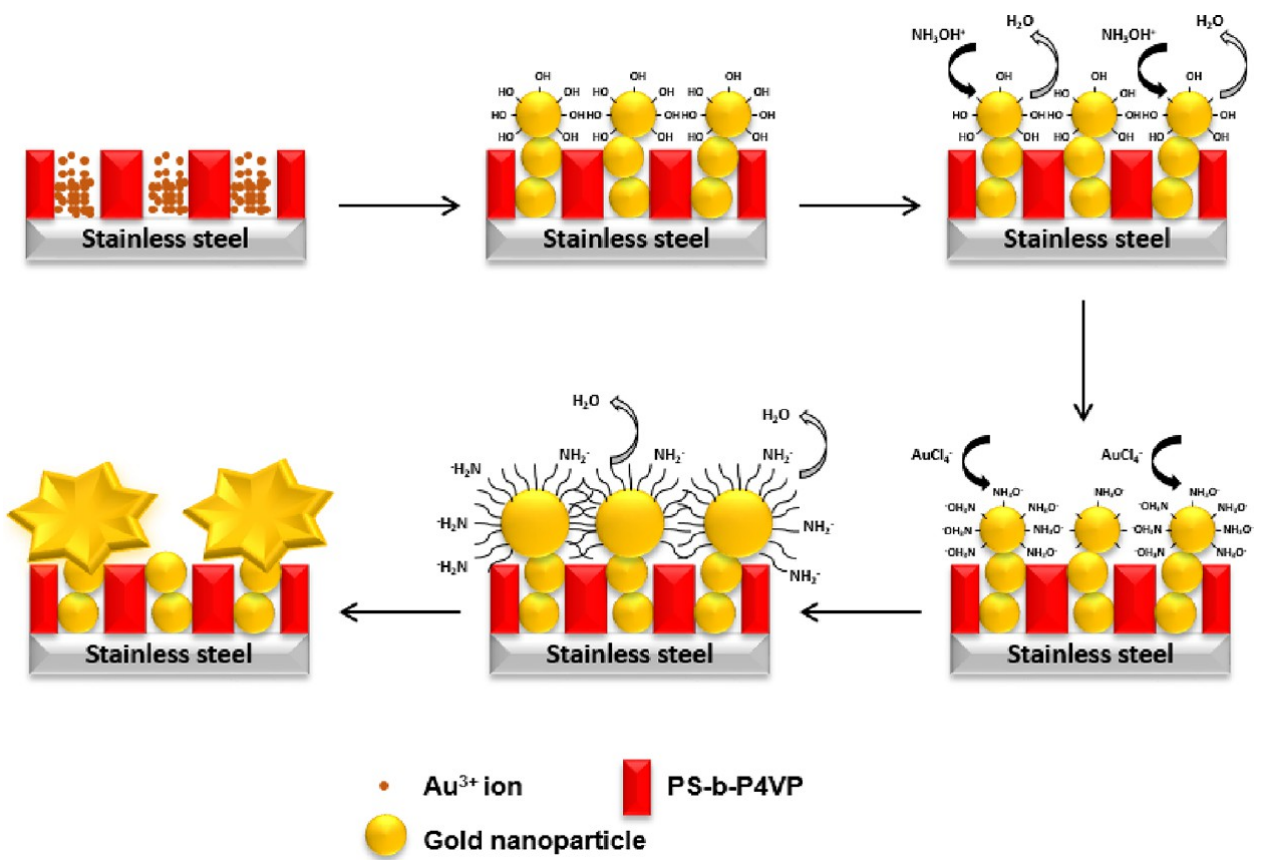

Figure 3. Schematic representation of AuNFs growth onto a nanopatterned surface by a template-mediated method.

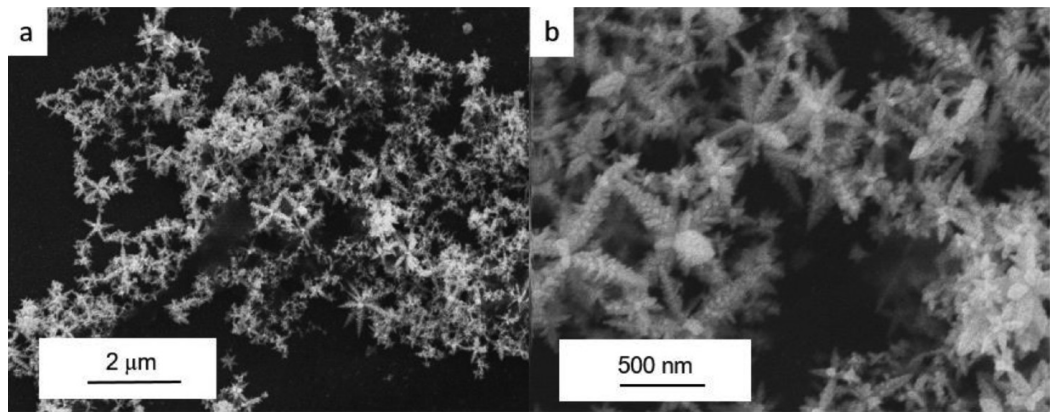

Figure 4. SEM images of the as-prepared Au flower-like structures obtained on stainless steel plates. (a) Scale bar: $2 \mu \mathrm{m}$. (b) Scale bar: $500 \mathrm{~nm}$.

For the local voltamperometry, the microcell was composed of a working electrode, which corresponded to the stainless steel plate coated with gold nanoflowers (AuNFs) connected to the potentiostat and a $200 \mu$ m diameter capillary made of silicon, a reference electrode of $\mathrm{Ag} / \mathrm{AgCl}$, and a platinium counter electrode. ${ }^{38}$ The experiments have been carried out in a $0.1 \mathrm{M} \mathrm{Na}_{2} \mathrm{SO}_{4}$ solution.

For global voltamperometry, a classical three-electrode device with a prepatterned sample as working electrode, a platinum counter electrode, and a $\mathrm{Ag} / \mathrm{AgCl}$ reference electrode was settled upon. The electrolyte was $0.1 \mathrm{M} \mathrm{Na}_{2} \mathrm{SO}_{4}$ solution.

\section{RESULTS AND DISCUSSION}

Growth Mechanism and Characterization of the $\mathrm{Au}$ Flower-like Structures. Au dendritic nanostructures have been synthesized using a solution-based reduction approach. These nanocrystals have been grown onto stainless steel plates templated with a nanostructured block copolymer (PS- $b$-P4VP) film recovered with gold seeds. The overall synthesis protocol is illustrated in Figure 3.

The substrates were first immersed into a colloidal gold solution followed by the addition of $\mathrm{N}_{2} \mathrm{H}_{4}$ reducing agent. In a typical reaction, gold salts are subsequently reduced from $\mathrm{Au}^{3+}$ to $\mathrm{Au}^{0}$. After this seeding step, gold nanoparticles (AuNPs) are covered by negative charges coming from hydroxyl ions $\left(\mathrm{HO}^{-}\right) .{ }^{39}$ Then, a structuring agent was used to reduce
$\mathrm{HAuCl}_{4}$ and to structure both the morphology and size of these specific Au structures. According to Mahksin et al., in this seeding growth method, hydroxylamine molecules play the role of reductant, but also accelerate the reduction of $\mathrm{Au}^{3+}$ on the surface of the seeds. After immersing gold-seeded plates into an aqueous solution of $\mathrm{NH}_{2} \mathrm{OH}$, molecules are rapidly and selectively adsorbed on the specific Au crystal planes, covering them with $\mathrm{NH}_{3} \mathrm{O}^{-}$groups. Larger sized AuNPs are formed covered with $\mathrm{NH}_{2}^{-}$groups via addition and diffusion of $\mathrm{Au}^{3+}$ ions. ${ }^{40}$ These groups act as shape-directing agents for initial branching, providing specific binding at some specific locations. According to $\mathrm{Lv}$ and co-workers, ${ }^{26}$ the $-\mathrm{NH}_{2}$ groups of cytosine molecules are likely to produce branched nanostructrures and could increase the branching power of structuring agents. Hence, the following reactions might be considered as a possible mechanism occurring during the gold nanoflowers (AuNFs) growth:

$$
4 \mathrm{Au}^{3+}+3 \mathrm{~N}_{2} \mathrm{H}_{4}+12 \mathrm{HO}^{-} \leftrightarrow 4 \mathrm{Au}^{0}+3 \mathrm{~N}_{2}+12 \mathrm{H}_{2} \mathrm{O}
$$

$$
\begin{array}{r}
\mathrm{Au}+\mathrm{AuCl}_{4}^{-}+4 \mathrm{HO}^{-}+\mathrm{NH}_{3} \mathrm{OH}^{+} \\
\leftrightarrow 2 \mathrm{Au}++\mathrm{NO}+4 \mathrm{Cl}^{-}+4 \mathrm{H}_{2} \mathrm{O}
\end{array}
$$



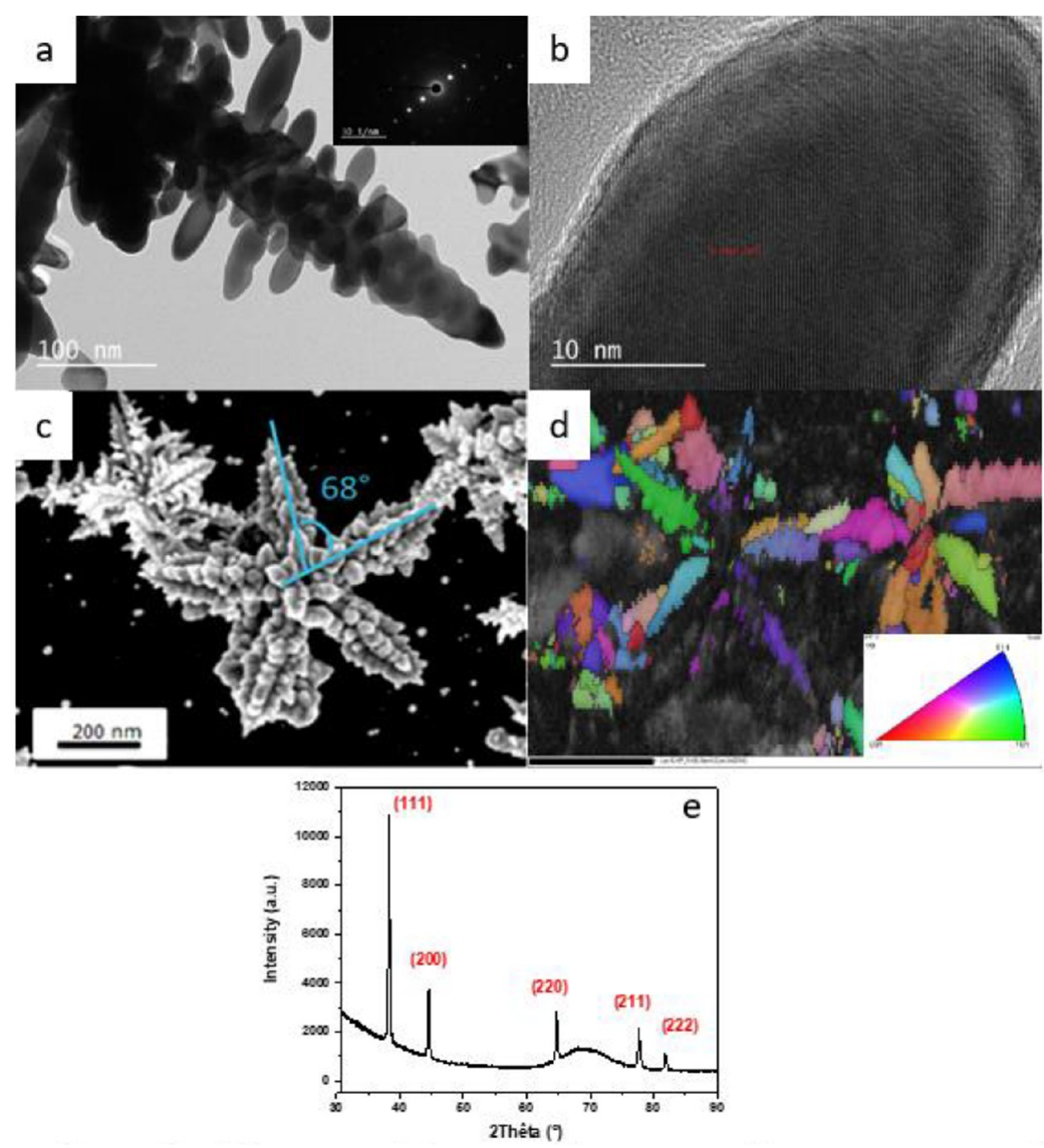

Figure 5. (a) HRTEM image of a trunk with symmetric leaves with the corresponding SAED pattern. (b) HRTEM of the area of a leaf. (c) HRSEM images of as-prepared Au flower-like structures. (d) EBSD analysis of one flower-like structure with corresponding colors. (e) Associated XRD pattern of gold flower-like structures.

Figure 4 shows typical scanning electron microscopy (SEM) images of $\mathrm{Au}$ dendritic structures at different magnifications. As is shown in Figure 4a, aggregated flower-like structures were formed with an average size of $500 \mathrm{~nm}$. Higher magnification (Figure 4b) reveals that hierarchical gold structures close to fivepointed stars have been obtained. They were composed of tips, which were evenly extended out, with the angle between each adjacent tip of $\sim 68^{\circ}$ (Figure $4 \mathrm{~b}$ ).

HRTEM was carried out to determine the crystal orientation of the obtained gold dendrites. As a result, they have been deposited on a gold grid. Figure 5a shows HRTEM images of a trunk with leaves with its corresponding selected area electron diffraction (SAED) patterns. The dendrites consist of a trunk with rod-like perpendicular leaves. The SAED pattern shows a perfect straight line of diffraction spots, which verifies that one dendrite contains a single crystalline face. HRTEM measurements also demonstrated this single crystalline nature at the tip areas of the branch, as shown in Figure $5 \mathrm{~b}$. The atomic lattice exhibits a $d$ spacing of $0.24 \mathrm{~nm}$ in the axial direction of the branch, with the $d$ spacing of (111) planes for the fcc Au crystal. The average angle between branches is on the order of $68^{\circ}$, as depicted in Figure $5 c$.
The XRD spectrum was also plotted to determine the crystal orientation of the obtained gold dendrite. Figure 5e shows a typical XRD spectrum of the hierarchical gold five-pointed star structures and exhibits sharp diffraction peaks located at $38.4^{\circ}$, $44.5^{\circ}$, and $62.7^{\circ}$ corresponding to $\{111\},\{200\}$, and $\{220\}$, respectively. They can be attributed to Au crystals with the fcc crystal system, indicating that dendrites are well-crystallized. Afterward, Figure 5d shows the EBSD orientation map of an overall gold nanoflower. On the mapping image, different crystallographic colors appear for each tip. This important result shows perfectly that each branch has its own crystallographic orientation of (101) or (111), which proves the growth of threedimensional Au nanoflowers.

Effect of the Reaction Conditions. Effect of $\mathrm{pH}$ on Gold Structures' Morphology. Investigations have been realized to evaluate the $\mathrm{pH}$-dependence of $\mathrm{HAuCl}_{4}$ reduction by hydroxylamine on the control of gold nanostructures' morphology growth at room temperature. Prepatterned substrates were immersed into $5 \mathrm{~mL}$ of $\mathrm{NH}_{2} \mathrm{OH}$ aqueous solution with $\mathrm{pH}$ varying from 4 to 8 for $45 \mathrm{~min}$, and then $50 \mu \mathrm{L}$ of $1 \%$ wt gold salts was added to initiate the reduction reaction. Figure 6 presents 


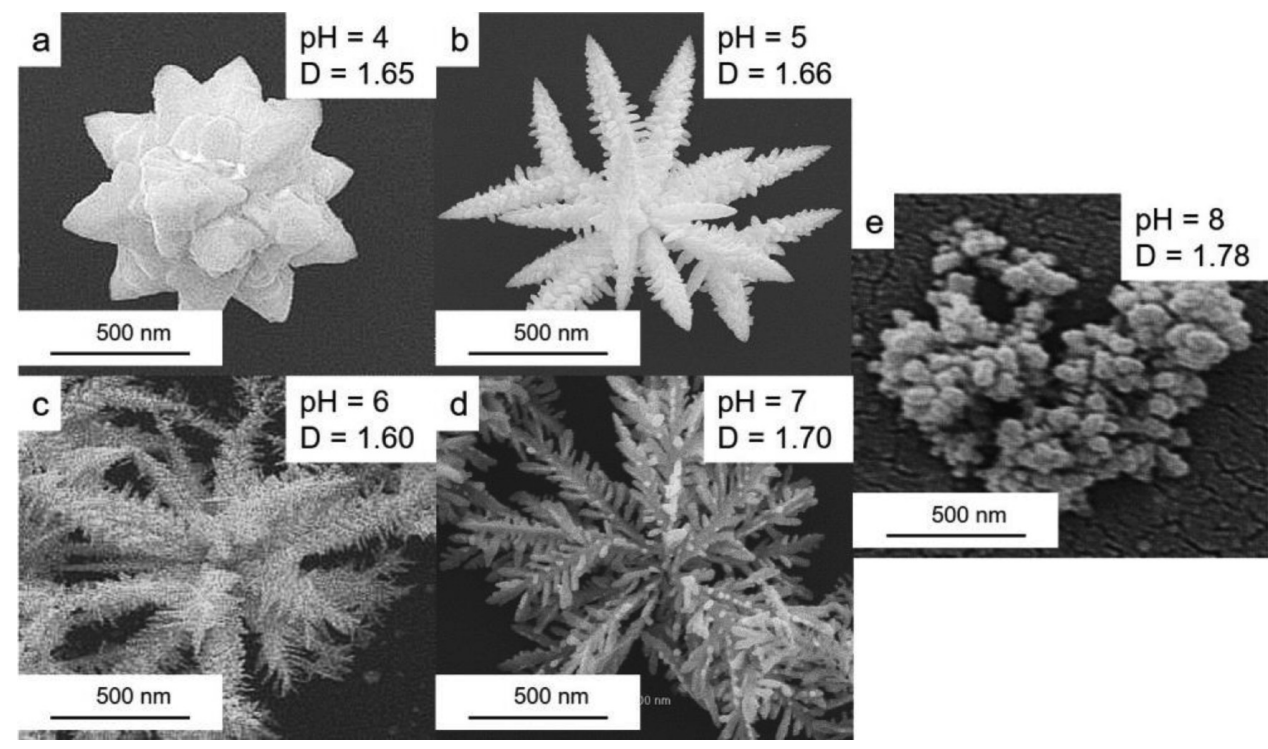

Figure 6. SEM images of different gold nanostructures grown onto prepatterned substrates by the wet chemical method as a function of the solution $\mathrm{pH}$ : (a) $\mathrm{pH} 4$, (b) $\mathrm{pH} \mathrm{5,} \mathrm{(c)} \mathrm{pH} \mathrm{6,} \mathrm{(d)} \mathrm{pH}$ 7, and (e) $\mathrm{pH}$ 8. The $\mathrm{pH}$ has been controlled with an ammoniac aqueous solution (500 mM). Scale bar: 500 nm. Monofractal dimensions $D$ have been calculated for each structure.
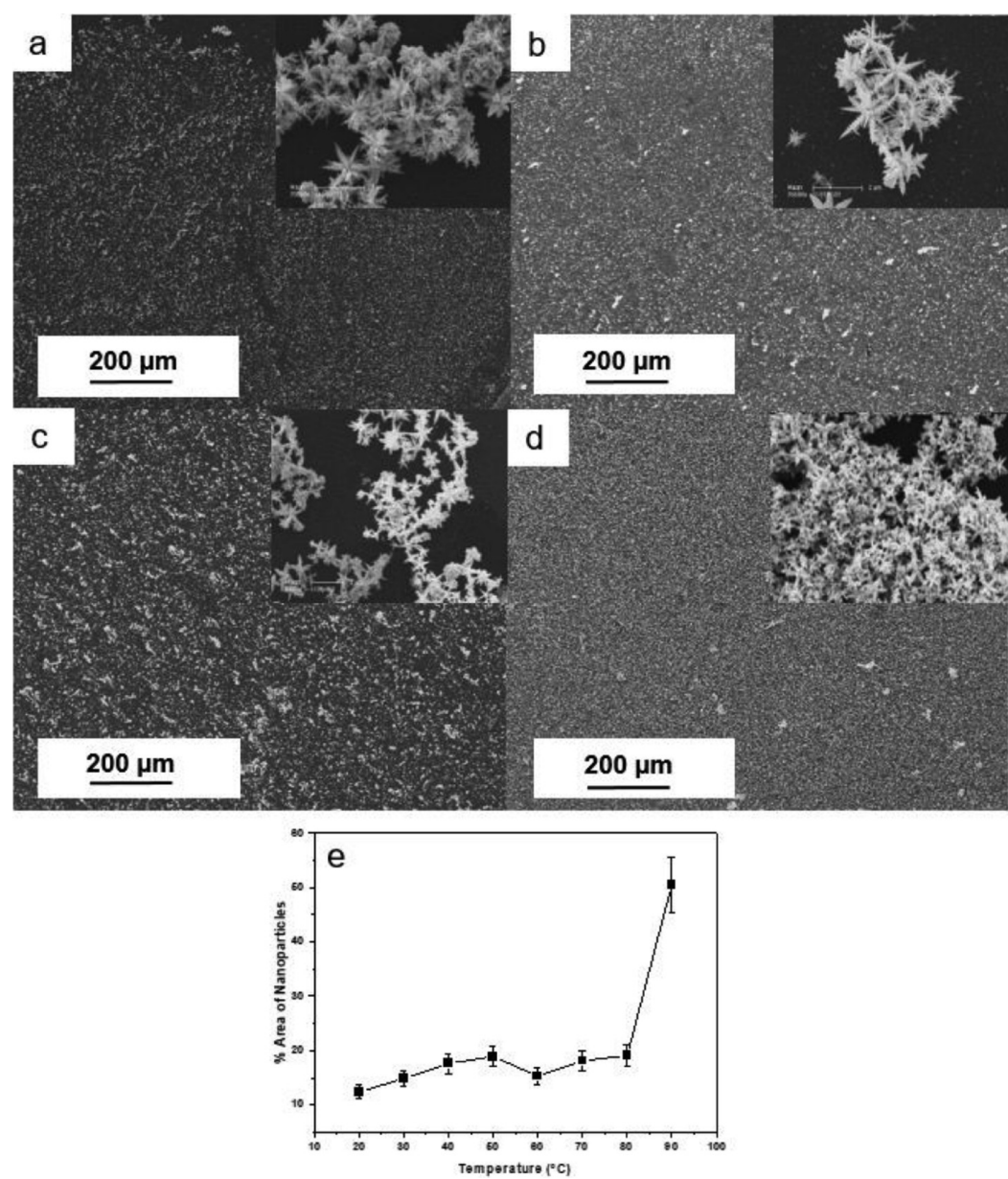

Figure 7. Typical SEM images of the Au flower-like structures grown onto prepatterned silicon wafers at different temperatures: $(\mathrm{a}) \mathrm{T}=20^{\circ} \mathrm{C},(\mathrm{b}) \mathrm{T}=$ $40^{\circ} \mathrm{C}$, (c) $T=60^{\circ} \mathrm{C}$, and (d) $T=80^{\circ} \mathrm{C}$. Scale bar: $200 \mu \mathrm{m}$. (e) Graph representing the average percentage coverage rate of gold structures (extracted from SEM images) as a function of reaction temperature.

SEM images of the crystals synthesized onto prepatterned selforganized gold seeds/PS- $b$-P4VP silicon wafers.
As shown in Figure 6a, at $\mathrm{pH} 4$, star-like gold structures were observed with an average diameter of around $1 \mu \mathrm{m}$. Both morphology and distribution of structures are presented as 

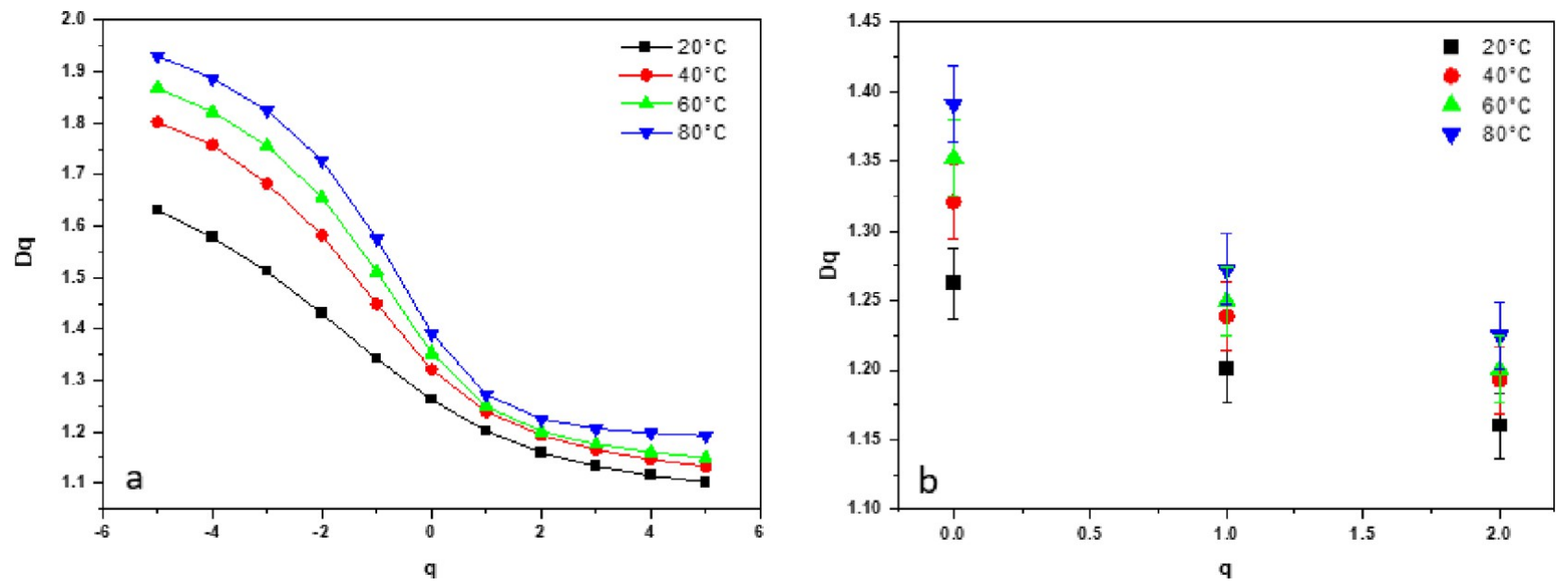

Figure 8. Multifractal analysis of SEM images of AuNFs structures. (a) Generalized dimension spectrum over the $[-5 ; 5]$ moment $q$ range for different reaction temperatures varying from 20 to $80^{\circ} \mathrm{C}$ and (b) generalized multifractal dimensions $D_{q}$ over the $[0 ; 2] q$ range with $Y$ error bars of substrate nanostructured surface at different temperatures from 20 to $80^{\circ} \mathrm{C}$.

heterogenic with coexistence of four-tipped quadraedric stars and eight-tipped octaedric stars. With a further increase of the $\mathrm{pH}$ up to 5, more aggregated flower-like gold structures were observed with an average diameter of $2 \mu \mathrm{m}$. It is clear that the developed flower-like structures exhibit several trunks with numerous rod-like leaves. At higher $\mathrm{pH}$ (6 or 7), more hyperbranched gold flower-like structures are formed. Figure $6 \mathrm{c}$ shows that gold structures start to connect to each other with formation of a tapered shape closer to a bush-like structure, as seen at an advanced stage in Figure 6d. Finally, Figure 6e shows that, at a basic $\mathrm{pH}$, several cracks in the copolymer thin film have appeared and anisotropic gold nanostructures have replaced the flower-shaped structures. The Ffractal dimension of each flowerlike structure has also been investigated. Results show that by increasing the $\mathrm{pH}$ up to 7 or more, the structures tend to grow in a $2 \mathrm{D}$ diffusion-limited aggregation cluster (Brownian tree with $D$ $=1.7$ ), whereas other structures grow in a $3 \mathrm{D}$ polymer motion without self-intersection $(D=1.66)$. In both cases, particles, during the growth process, follow a Brownian motion with haphazard and disorderly diffusion. ${ }^{41}$

These above results suggest that the acidity and basicity of reaction solutions can kinetically favor or inhibit the reduction rate of gold ions, which can affect the initial gold nucleation process. ${ }^{42}$ It is known that the reductive activity of hydroxylamine increases with a higher $\mathrm{pH}$ value, which could explain the appearance of longer branches at this $\mathrm{pH}$. Moreover, Zhao and co-workers suggest in their experiments that chlorine ions have also a key effect on the intraparticle ripening process of the nanoflowers. ${ }^{43}$ Hence, under neutral or basic conditions, the possible binding of the chlorine ions with gold atoms is mainly forbidden due to the increase of the hydroxyl groups concentration. This results in facilitating the movement of gold atoms from one facet to another facet and allowing the growth of specific branched gold structures. On the contrary, at high acidity, the reduction of gold ions could be inhibited and may induce delays in the branch expansion, leading to the growth of $2 \mathrm{D}$ planar structures.

Finally, $\mathrm{pH}$ represents one of the key factors to grow typical branched gold nanocrystals. In addition, a sufficient reductive activity of hydroxylamine molecules represents a precondition to ensure the proper arrangement of ions at the surface of particles, which allows the growth of dendritic-like structures.
This study has perfectly shown that the reduction is much faster at higher $\mathrm{pH}$ (close to neutral) contrary to lower $\mathrm{pH}$, proving the $\mathrm{pH}$-dependence of the reduction reactions and the structuring effect of the molecules at the surface during the growth of flowerlike structures.

Effect of the Reaction Temperature. Besides the $\mathrm{pH}$ effect, an appropriate reaction temperature remains also essential for the formation of $\mathrm{Au}$ dendritic nanocrystals, as this parameter greatly influences the reductive activity of the structuring agents and the system diffusion constant. ${ }^{44}$ Experiments at different temperatures, varying from 20 to $90{ }^{\circ} \mathrm{C}$ with a $10{ }^{\circ} \mathrm{C}$ step, have been investigated. Temperature has been controlled with a closed double-jacketed glass cell and a heating bath. Figure 7 displays SEM images of the structured surfaces obtained at four different reaction temperatures.

It is observable that the reaction temperature does not really impact the hierarchical architecture of the individual flowers. Nevertheless, a low reaction temperature seems to form both alternative flowers and spheres, while only gold flower-like structures are visible at high reaction temperatures above $60{ }^{\circ} \mathrm{C}$ (Figure 7c). In addition, the observation of the SEM images shows that the nanoparticles' coverage rate seems to be mainly similar between 20 and $60{ }^{\circ} \mathrm{C}$ (Figure $7 \mathrm{a}-\mathrm{c}$ ), while an increase of the reaction temperature up to $90{ }^{\circ} \mathrm{C}$ causes a deep enhancement of the distribution of $\mathrm{Au}$ nanostructures (Figure $7 \mathrm{e}$ ). It could be explained by the convergence of the reaction temperature close to the boiling point of the solvent (water). In this case, this phenomenon could cause a strong rise of the mixture entropy, which will enable a rapid reduction of the $\mathrm{AuCl}_{4}{ }^{-}$ions to $\mathrm{Au}^{0}$ on the prepatterned samples.

Previous work realized by Zhang et al. has shown that the reaction temperature impacts both the reducing power of the structuring agent and diffusion rate of additives in the medium. A low temperature seems to cause too slow of a reduction of small gold particles to ensure the three-dimensional growth of nuclei, while higher temperature increases the possibility to ensure three-dimensional growth of branched gold nanostructures. ${ }^{45}$ Consequently, the temperature represents an essential parameter to avoid aggregation of the structures and ensure the hierarchical arborescence of flowers. In particular, the high diffusion rate allows one to improve the seed density and separation of the structures, one from another. Control of the 


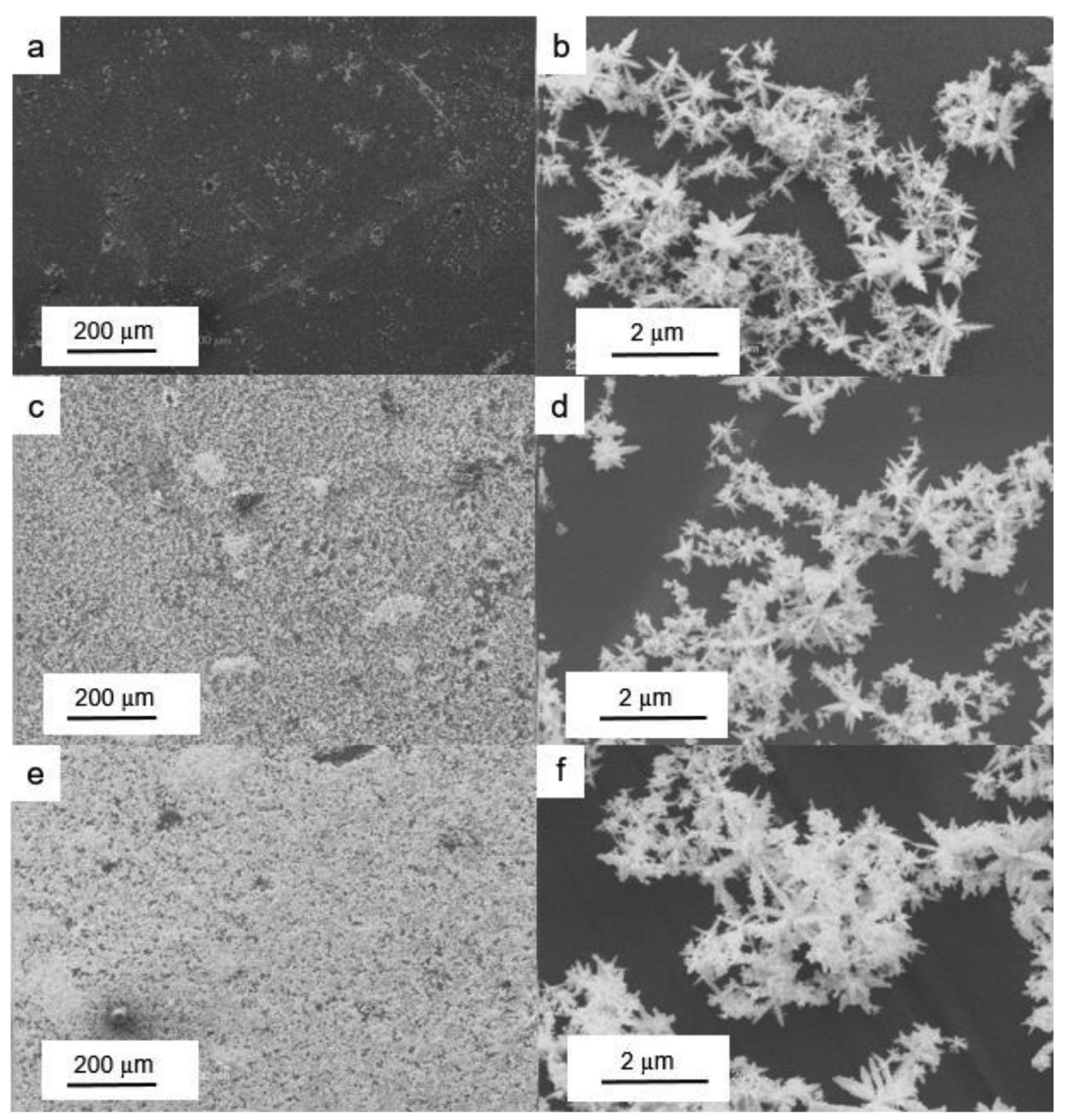

Figure 9. SEM images of Au flower-like structures grown onto prepatterned stainless steel substrates and synthesized at different amount of gold salt solution: (a) $50 \mu \mathrm{L}$, (b) zoom in of panel a, (c) $200 \mu \mathrm{L}$, (d) zoom in of panel c, (e) $500 \mu \mathrm{L}$, and (f) zoom in of panel e.

reaction temperature during the entire reaction allows formation of more homogeneous and well-dispersed nanostructures at the sensor surface.

In order to quantify these data, multifractal analysis has been realized. This analysis has allowed comparing of $D_{0}, D_{1}$, and $D_{2}$ values calculated for each SEM image of AuNFs surfaces realized at different reaction temperatures varying from 20 to $80{ }^{\circ} \mathrm{C}$, as depicted in Figure 8. By comparing sample surfaces at each temperature, it has been observed that a higher temperature corresponds to a higher $D_{0}$, which means that the surface coverage rate increases with temperature. Indeed, $D_{0}$ increases from 20 to $80{ }^{\circ} \mathrm{C}$, from 1.27 up to 1.39 ; this corresponds to a higher apparent space coverage of flower-like structures, as observed in the SEM images. Then, $D_{1}$ is correlated to the Shanon entropy. A higher $D_{1}$ value meant that the degree of disorder increased as well. The disorder is increasing with the increase of surface coverage until $80^{\circ} \mathrm{C}$. Finally, the correlation dimension $\mathrm{D}_{2}$ increases, too, with temperature; this behavior corresponds to a decrease of the Au clustering level (nanoflower aggregation).

The multifractal analysis has provided a unique tool to gain a better understanding of the microstructure growth and distribution onto the surface of samples. By studying the influence of temperature on the $\mathrm{Au}$ flower-like structures growth, information on and indirect quantification of the coverage rate, homogeneity, and cluster level on the surface have been obtained. Finally, a $60 / 70{ }^{\circ} \mathrm{C}$ reaction temperature has been resolved to grow flower-like structures onto prepatterned substrates. The distribution has been then optimized, leading to the formation of hyperbranched nanoflowers through a selforganization process under nonequilibrium conditions.

Effect of Gold Salt Concentration. The pH-dependent method offers highly interesting perspectives for the formation of Au flower-like structures. However, the very low coverage rate of the sensor surface by AuNFs after addition of a few tens of microliters of $\mathrm{HAuCl}_{4}$ shows us the limit of the crystal growth process. However, by varying the amount of gold salts in the solution, the final distribution of the flowers could have been tuned easily. Here in a typical synthesis, the $\mathrm{pH}$ has been fixed close to 6.5 and the temperature controlled by the doublejacketed glass cell at $70{ }^{\circ} \mathrm{C}$, with an aqueous gold solution $(25$ $\mathrm{mM}$ ) and an aqueous $\mathrm{NH}_{2} \mathrm{OH}$ solution $(20 \mathrm{mM})$. Different amounts of gold solution have been studied by varying the injection from 50 to $500 \mu \mathrm{L}$.

As expected, the density of AuNFs on the substrates increases as a function of the Au salt amount injected into the growth solution. This parameter allows a more precise control of the density of AuNFs on the samples, but it does not avoid the aggregation of flowers. However, concentration boundaries could have been observed where formation of NFs is more important. Indeed, our results show that the more relevant gold salt solution amount to avoid structure aggregation while 

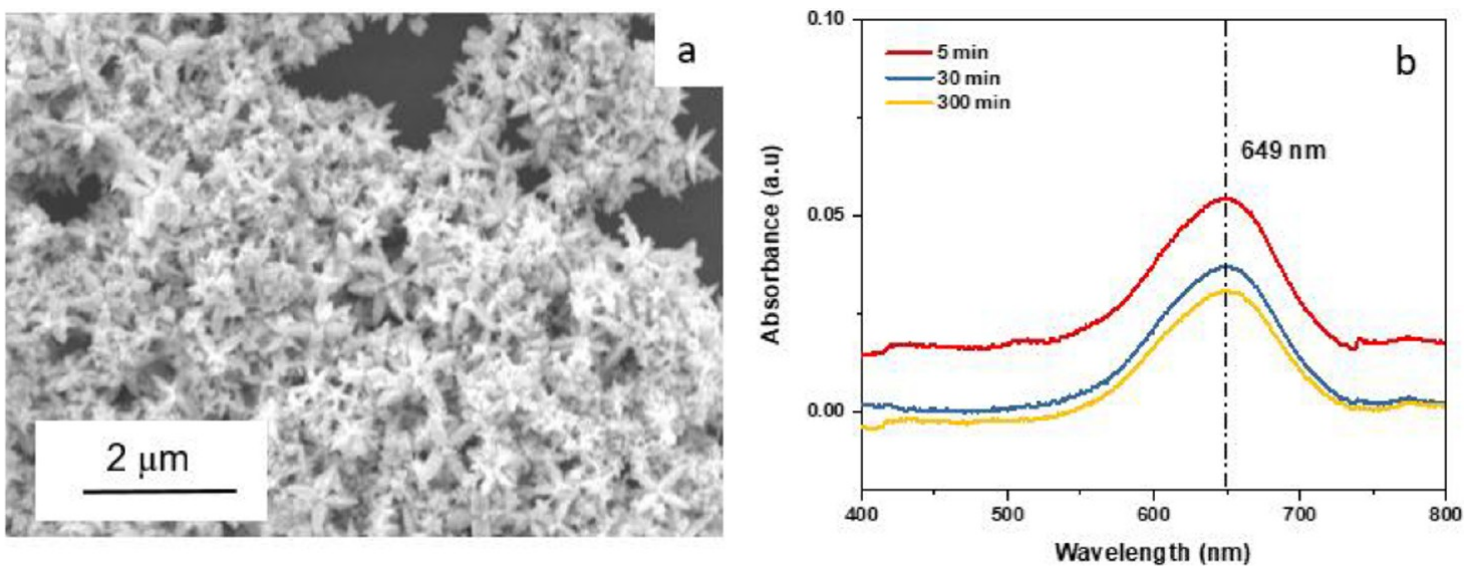

Figure 10. (a) SEM image of AuNFs deposited by a chemical pH-dependent method onto prepatterned stainless steel substrates. (b) Corresponding UV-visible spectra recorded at three adsorption times in CBB solution: 5, 30, and $300 \mathrm{~min}$.
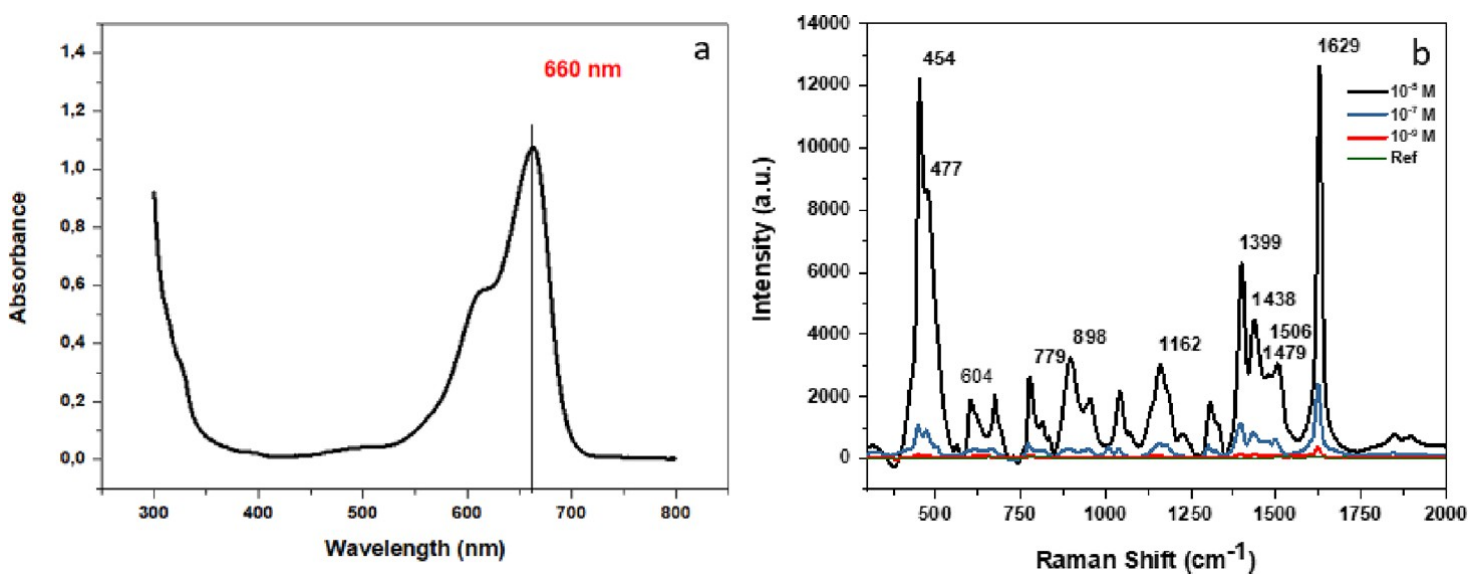

Figure 11. (a) UV-vis spectrum of MB and (b) SERS spectra of MB adsorbed on gold flower-like structures at different concentrations. Reference = $50 \mathrm{~nm}$ gold coating deposited on a stainless steel substrate.

ensuring a high AuNFs coverage rate on the surface is in the interval of $100-200 \mu \mathrm{L}$ of $\mathrm{HAuCl}_{4}$. This result is reinforced by the fact that, with a too high quantity of metallic salts, the shape of the structures starts to be affected, too (Figure 9f), and aggregation increased as well.

Electrocatalytic Activity of Au Dendrites. The optical properties of AuNF structures deposited onto the sensor surface have been investigated. The morphology of dendritic nanostructures, and especially the presence of their neighboring branched blocks and numerous tips at the branch apex, allows one to induce a local electromagnetic field under irradiation of a laser at a perfect wavelength. In such conditions, the appearance of a large amount of hot-spots at the apex of the flower branches or in between closed branches contributes to the enhancement of the induced localized plasmon field. In order to amplify the electrocatalytic activity of the nanostructured surface with both the required structure and cover density, optimized amounts of reactants and particular reaction parameters have been determined for the preparation of prepatterned samples $[\mathrm{pH}$ 6.5, $\mathrm{T}=70{ }^{\circ} \mathrm{C}, 100 \mu \mathrm{L}$ of $\mathrm{HAuCl}_{4}$ aqueous solution $\left.(25 \mathrm{mM})\right]$. This specific electrocatalytic activity could have been followed by optical spectroscopy and also voltammetry techniques.

ADECA Method. The ADECA colorimetric method allows one to quantify the number of active sites on a surface and evaluate the detection performance of AuNF structured surfaces. Three absorption times of $\mathrm{CBB}$ molecules on these surfaces have been recorded with UV-visible spectroscopy. Figure 10 represents SEM images of AuNFs and the variation of the absorbance of $\mathrm{CBB}$ on these structures as a function of three different absorption times. UV-visible spectra display the presence of a broad peak at around $650 \mathrm{~nm}$, corresponding to the basic form of CBB. The absorbance values of the maximum peaks increase with increasing absorption time, ranging from 0.03 and $0.06 \mathrm{au}$. The corresponding number of active sites (AS) calculated from eq 5 are $1.27 \times 10^{15}, 1.35 \times 10^{15}$, and $2.16 \times 10^{15}$ AS cm$~^{-2}$ for 5, 30, and 300 min of CBB absorption, respectively. As a result, the number of active sites increases as a function of absorption times, as expected. Nonetheless, an average of $10^{15}$ AS $\mathrm{cm}^{-2}$ has been estimated for flower-like structures depicted in Figure 10a.

SERS Activity of Au Flower-like Structures. Anisotropic Au nanostructures have been usually characterized by Raman spectroscopy to evaluate their SERS effects, depending on their size and morphology.

Figure 11a displays the UV-visible spectrum of $\mathrm{MB}$ and Figure $11 \mathrm{~b}$ shows the Raman spectra of $\mathrm{MB}$ molecules at different molar concentrations adsorbed onto AuNFs structures. The UV-visible adsorption band of MB leads to the appearance of a main intense peak at $649 \mathrm{~nm}$, as displayed in Figure 11a. Investigation of the plasmon resonance adsorption of AuNFs has been done by integrating sphere spectroscopy. Results of the evolution of the reflectance of AuNFs structured surfaces vs 
Table 1. Band Assignments and Enhancement Factors (G) Calculated from SERS Spectra Displayed in Figure 11b

\begin{tabular}{|c|c|c|c|c|c|c|c|}
\hline \multicolumn{2}{|c|}{ assignment } & $\delta(\mathrm{C}-\mathrm{N}-\mathrm{C})$ & $\delta(\mathrm{C}-\mathrm{S}-\mathrm{C})$ & $\nu(\mathrm{C}-\mathrm{N})$ & $\alpha(\mathrm{C}-\mathrm{N})$ & $\nu(\mathrm{C}-\mathrm{N})$ & $\nu(\mathrm{C}-\mathrm{C})$ ring \\
\hline \multicolumn{2}{|c|}{ raman shift $\left(\mathrm{cm}^{-1}\right)$} & 454 & 604 & 1162 & 1399 & 1438 & 1629 \\
\hline \multirow[t]{3}{*}{$G$ factor } & $10^{-5} \mathrm{M}$ & $1.2 \times 10^{5}$ & $1.9 \times 10^{4}$ & $3.1 \times 10^{4}$ & $6.4 \times 10^{4}$ & $4.4 \times 10^{4}$ & $1.3 \times 10^{5}$ \\
\hline & $10^{-7} \mathrm{M}$ & $1.1 \times 10^{4}$ & $3.1 \times 10^{3}$ & $4.9 \times 10^{3}$ & $1.2 \times 10^{4}$ & $8.1 \times 10^{3}$ & $2.5 \times 10^{4}$ \\
\hline & $10^{-9} \mathrm{M}$ & $1.8 \times 10^{3}$ & $3.1 \times 10^{2}$ & $1.8 \times 10^{2}$ & $1.7 \times 10^{3}$ & $1.4 \times 10^{2}$ & $3.6 \times 10^{3}$ \\
\hline
\end{tabular}
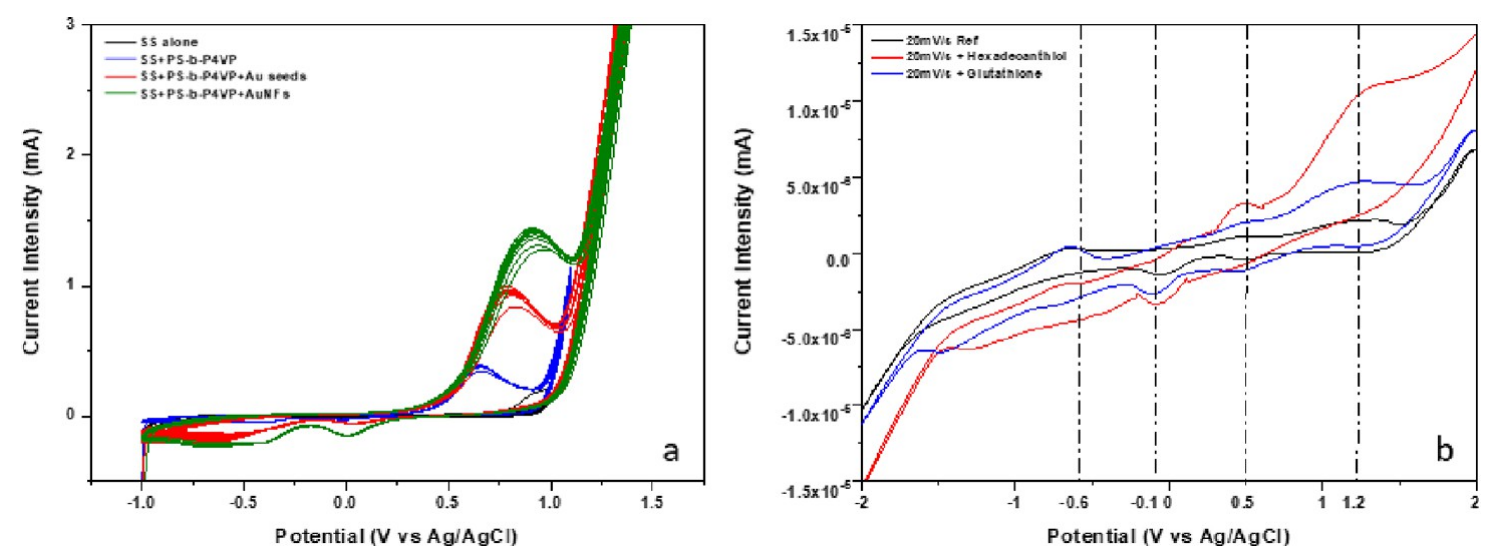

Figure 12. (a) Global cyclic voltammograms $\left(0.1 \mathrm{M} \mathrm{Na}_{2} \mathrm{SO}_{4}, \mathrm{pH} 5,20 \mathrm{mV} / \mathrm{s}\right.$, cycle 10) of stainless steel substrates alone (black curve) and those prepatterned with PS- $b$-P4VP (blue curve), coated with gold seeds (red curve), and finally covered with gold flower-like structures (green curve). (b) Local cyclic voltammograms of stainless steel samples covered by gold flower-like structures at a scan rate of $20 \mathrm{mV} / \mathrm{s}$ in a solution of $0.1 \mathrm{M} \mathrm{Na} \mathrm{SO}_{4}$ reference sample (black curve), sample immersed in a hexadecanethiol solution at a concentration of $10^{-9} \mathrm{M}$ (red curve), and sample immersed in a glutathione solution at a concentration of $10^{-9} \mathrm{M}$ (blue curve).

wavelength display the appearance of a minimum peak at 500 $\mathrm{nm}$ (Figure S2, Supporting Information). As a result, neither the plasmon band of the AuNFs nor the adsorption wavelength of $\mathrm{MB}$ are in accordance; the analysis of the SERS effect of MB adsorbed onto AuNFs will be with regard to SERS conditions (and not SERRS ones). ${ }^{46,47}$

The analysis of the Raman spectra of MB adsorbed onto AuNFs displays several main characteristic peaks, which are of interest for a simple study of the enhancement factor (EF). The two main intense peaks correspond to the vibration of the $\mathrm{C}-$ $\mathrm{N}-\mathrm{C}$ skeleton bonding at $445 \mathrm{~cm}^{-1}$ and C-C bonding at 1626 $\mathrm{cm}^{-1}$. In addition, results show that the SERS signal increases greatly when the concentration of $\mathrm{MB}$ increases from $10^{-9}$ to $10^{-5} \mathrm{M}$

The enhancement factor per molecule $(G)$ has been calculated using the formula

$$
G=\frac{I_{\mathrm{SERS}}}{I_{\mathrm{ref}}} \frac{N_{\mathrm{ref}}}{N_{\mathrm{SERS}}}
$$

where $I_{\text {SERS }}$ is the intensity of the SERS spectrum, $I_{\text {ref }}$ is the intensity of the Raman spectrum of the same peak, $N_{\text {ref }}$ is the number of molecules excited in the reference sample, and $N_{\text {SERS }}$ is the number of molecules covering the structured sample within the laser spot area. Consequently, $I_{\text {SERS }} / N_{\text {SERS }}$ is the SERS integrated intensity of some typical bands reduced to a single adsorbed molecule, and $I_{\text {ref }} / N_{\text {ref }}$ is the corresponding spontaneous Raman intensity of the same band. To determine the values of those four parameters, a similar procedure to that described in the literature has been followed. ${ }^{48}$ Using an $100 \times$ objective lens, the area of the laser spot size has been estimated as $80 \mu \mathrm{m}^{2}$. Moreover, the area of a single molecule of MB has been calculated to be approximatively $2 \mathrm{~nm}^{2}$. Thus, the number of MB molecules adsorbed on the $80 \mu \mathrm{m}^{2}$ sample (under the laser spot) has been evaluated as $N_{\text {SERS }}=4 \times 10^{7}$. In such conditions, the scattering volume of the laser containing the $\mathrm{MB}$ molecules for the reference sample was evaluated as $79000 \mu \mathrm{m}^{3}$. As a result, the number of $\mathrm{MB}$ molecules included in this scattered area, for a $10^{-3} \mathrm{M}$ solution of $\mathrm{MB}$ in water, has been estimated to be $N_{\text {ref }}=4.75 \times 10^{10}$. Therefore, the enhancement per molecule $G$ was thus evaluated using the following equation:

$$
G=1.2 \times 10^{3} \frac{I_{\text {SERS }}}{I_{\text {ref }}}
$$

The enhancement factors per molecule $(G)$ have been calculated for the different main Raman peaks characteristic of the MB molecules and are displayed in Table 1. Results show that the lower the solution concentration is, the lower the enhancement factor $G$ is, as expected. However, those enhancement factor data indicate the high efficiency of the asprepared flower-like gold nanostructures as SERS supports. Indeed, the literature suggests that the dendritic nanostructures provide high enhancement due to their sharp corners, edges, high surface-to-volume ratio, and nanoscale junctions, which can be considered as "hot-spots". Hence, the morphology of gold structures is able to induce dramatically different enhancement of the Raman signal and could differentiate chiral molecules, as observed in the literature. ${ }^{49,50}$

Catalytic Activity-Glutathione/Hexadecanethiol. The electrocatalytic activities of that gold dendritic structure have also been investigated by cyclic voltammetry. The first "global" electrochemical measurements have been performed in an electrolytic bath $\left(0.1 \mathrm{M} \mathrm{Na}_{2} \mathrm{SO}_{4}\right)$ at a scan rate of $20 \mathrm{mV} / \mathrm{s}$. Figure 12 displays the different voltammograms corresponding to the reference and nanostructured samples: stainless steel plates (SS, black curve) or stainless steel plates covered by PS- $b$ P4VP (blue curve), PS- $b$-P4VP + gold seeds (red curve), and PS- $b$-P4VP + gold seeds + AuNFs (green curve).

The cyclic voltammograms displayed in Figure 12a reveal a broad large peak between 0.6 and $0.9 \mathrm{~V}$. It may correspond to the oxidation of gold into gold salts. Moreover, another oxidation 
reaction takes place after $1.2 \mathrm{~V}$, which corresponds to the oxidation of water into oxygen in an acidic electrolyte or the oxygen evolution reaction (OER). This simple experiment allows one to show the difference observed in the electrochemical response of the working electrode varying from a sample just coated with copolymer and seeds or alone and a sample covered with AuNFs. ${ }^{51}$ The overall intensity strongly increases after growth of AuNFs on the surface. The corresponding oxidation reactions are the following:

$$
\begin{aligned}
& \mathrm{Au}^{0}+4 \mathrm{Cl}^{-} \leftrightarrow \mathrm{AuCl}_{4}^{-}+3 \mathrm{e}^{-} \\
& 2 \mathrm{H}_{2} \mathrm{O} \leftrightarrow \mathrm{O}_{2}+4 \mathrm{H}^{+}+4 \mathrm{e}^{-}
\end{aligned}
$$

These preliminary results show that the electrochemical activity is significantly modified by the growth of the AuNFs onto the substrate. Dendrites might appear to be good candidates for enhancing the electrocatalytic properties of the active surface and allowing a significant detection of molecules.

A second "local" electrochemical investigation has been performed on samples coated by PS-b-P4VP and Au-flower-like structures. Three different samples have been immersed in a $10^{-9} \mathrm{M}$ aqueous solution of gluthatione (GSH) and hexadecanethiol (HDT). Figure 12b displays the evolution of the electrochemical peaks as a function of the adsorbed molecule compared to a reference (substrate without adsorption).

The distribution of AuNFs onto the substrates is quite similar on all the investigated samples. In the entire voltammogram, four peaks appear. Two main oxidation peaks can be observed at 1.2 and $0.5 \mathrm{~V}$ and two other reduction peaks are seen at 0 and $-0.5 \mathrm{~V}$. The black curve, corresponding to the reference sample, displays four peaks with a very low intensity. This might be explained by the fact that no molecules have been adsorbed on it due to the absence of structuration. The two other curves (blue and red) represent the voltammograms of AuNFs after immersion into a GSH or HDT solution, respectively. A strong increase of the oxidation hysteresis has been observed on both voltammograms after adsorption of the different molecules onto the AuNFs. The slope of the HDT voltammogram is higher than that of the GSH-coated AuNFs, showing a difference in the kinetics of the oxidation reaction at the electrode. Investigation has been focused on the oxidation of gold reaction (OGR) peak appearing at a potential superior or equal to $1.2 \mathrm{~V}$. Indeed, the AuNFs structuration is able to discriminate the OGR peak as a function of the adsorbed molecule. ${ }^{52,53}$ The maximum of the peak for the OGR appears at $1.2 \mathrm{~V}$ for GSH and has been shifted to higher potential for HDT. Results shows that this OGR can occur at the same potential as the oxidation of GSH and HDT molecules. Indeed, the current intensity has reached $5.2 \times 10^{-5}$ A for GSH and $1.1 \times 10^{-4} \mathrm{~A}$ for HDT. Additional investigations should be done to show the influence of the structuration on the electrochemical response, especially the tip effect, and the limit of detection. However, these preliminary results are quite encouraging and show the sensitivity and selectivity of AuNFs through their electrochemical response after adsorption of a specific simple organic molecule.

\section{CONCLUSION}

In summary, a simple and controlled templated method has been developed for the synthesis of Au dendritic nanostructures.

This technique, contrary to many others, remains cheap and allows one to grow nanostructures on large areas. Beside the stainless steel plates, which could be replaced by other substrates (Si wafers, ITO, 306L stainless steel), the template fabrication can offer the possibility to deposit a soft template based on the phase separation of the mixture PS-b-P4VP/HABA at low cost, with an easy-to-make process and significant reproducibility. This nanoporous template enables one to have a better control of the distribution of gold nanostructures on the surface of samples initially by the insertion of gold seeds as growing points into the nanopores.

The resolution of physicochemical parameters $(\mathrm{pH}$, temperature) and the amounts of reactants $\left(\mathrm{HAuCl}_{4}, \mathrm{NH}_{2} \mathrm{OH}\right)$ has enabled as better control the distribution of gold flower-like structures by the hydroxylamine approach. Both morphology and coverage rate have been first characterized by the monofractal and multifractal analysis method, respectively, and then optimized on the overall surface of samples. Particularly, the multifractal analysis has provided a tool to gain a better understanding of the microstructure growth and distribution.

The as-prepared Au nanoflowers displayed excellent electrocatalytic properties as highly Raman-active structure surfaces and could be used as microsensors, allowing optical detection of low concentrations of adsorbed organic molecules (methylene blue). Furthermore, the electrochemical experiments suggested that the sensitivity of the surface is dependent on the nature of both adsorbed molecules. A perspective of this work would be to measure the photocatalytic activity at the apex of the tip simultaneously with an electrocatalytic reaction. ${ }^{54}$

In the long-term, a microelectromechanical systems (MEMs) generic platform could be developed to allow detection of very low traces of targeted molecules (amino acids) or biological bodies (cell, virus). The final objectives would be to obtain qualitative and quantitative data on the adsorbed molecules on the nanostructured surfaces incorporated in a microship. The physicochemical properties of the Au nanoflowers have shown excellent sensitivity (SERS) and durability (gold), which could be expanded by functionalization of the tips. MEMs are gaining notoriety for biosensing applications, due to their small size, low power consumption, and high integrability into microelectronic devices for implantable sensing applications.

\section{ASSOCIATED CONTENT}

\section{SI Supporting Information}

The Supporting Information is available free of charge at https://pubs.acs.org/doi/10.1021/acs.langmuir.0c01857.

Calibration curve of a silicon (100) wafer, scheme of the microcell used for the electrochemical analysis, and reflectance spectrum of AuNFs carried out by UV-vis integrating sphere spectroscopy (PDF)

\section{AUTHOR INFORMATION}

\section{Corresponding Author}

Pierre Bauer - Université Grenoble Alpes, Institut Neel, CNRS/ UGA UPR2940, 38042 Grenoble, France; 이이.org/00000002-1745-4557; Email: pierre.bauer05@orange.fr

\section{Authors}

Karine Mougin - Universite de Strasbourg, Universite de Haute Alsace, Institut de Science des Materiaux, 68057 Mulhouse, France

Delphine Faye - Centre Nationale d'Etudes Spatiales, 31400 Toulouse, France

Arnaud Buch - Laboratoire LGPM-CentraleSupelec, 91190 Gifsur-Yvette, France 
Pierre Ponthiaux - Laboratoire LGPM-CentraleSupelec, 91190 Gif-sur-Yvette, France

Vincent Vignal - Laboratoire Interdisciplinaire Carnot de Bourgogne, UMR 6303 CNRS-Université de Bourgogne FrancheComte, 21078 Dijon, France

Complete contact information is available at:

https://pubs.acs.org/10.1021/acs.langmuir.0c01857

\section{Notes}

The authors declare no competing financial interest.

\section{ACKNOWLEDGMENTS}

We gratefully acknowledge financial support from the Centre Nationale d'Etudes Spatiales, the Fondation de l'Ecole de Chimie de Mulhouse, and the Centre National de la Recherche Scientifique.

\section{REFERENCES}

(1) Hu, Y.; Pan, N.; Zhang, K.; Wang, Z.; Hu, H.; Wang, X. Fabrication of Dendrite-like Au Nanostructures and their Enhanced Photoluminescence Emission. Phys. Status Solidi A 2007, 204, 33983404.

(2) Ye, W.; Yan, J.; Ye, Q.; Zhou, F. Template-free and Direct Electrochemical Deposition of Hierarchical Dendritic Gold Microstructures: Growth and their Multiple Applications. J. Phys. Chem. C 2010, 114, 15617-15624.

(3) Pingarron, J. M.; Yanez-Sedeno, P.; Gonzalez-Cortes, A. Gold Nanoparticle-based Electrochemical Biosensors. Electrochim. Acta 2008, 53, 5848-5866.

(4) Shu, H.; Cao, L.; Chang, G.; He, H.; Zhang, Y.; He, Y. Direct Electrodeposition of Gold Nanostructures onto Glassy Carbon Electrodes for Non-Enzymatic Detection of Glucose. Electrochim. Acta 2014, 132, 524-532.

(5) Zen, J.-M.; Hsu, C.-T.; Senthil Kumar, A.; Lyuu, H.-J.; Lin, K.-Y. Amino Acid Analysis using Disposable Copper Nanoparticle Plated Electrodes. Analyst 2004, 129, 841-845.

(6) Ye, W.; Chen, Y.; Zhou, F.; Wang, C.; Li, Y. Fluoride-Assisted Galvanic Replacement Synthesis of Ag and Au Dendrites on Aluminium Foil with Enhanced SERS and Catalytic Activities. J. Mater. Chem. 2012, 22, 18327-18334.

(7) Lu, G.; Li, C.; Shi, G. Synthesis and Characterization of 3D Dendritic Gold Nanostructures and their use as Substrates for SERS. Chem. Mater. 2007, 19, 3433-3440.

(8) Huang, T.; Meng, F.; Qi, L. Controlled Synthesis of Dendritic Gold Nanostructures Assisted by Supramolecular Complexes of Surfactant with Cyclodextrin. Langmuir 2010, 26, 7582-7589.

(9) Ye, W.; Wang, D.; Zhang, H.; Zhou, F.; Liu, W. Electrochemical Growth of Flower-like Gold Nanoparticles on Polydopamine Modified ITO Glass for SERS Application. Electrochim. Acta 2010, 55, 20042009.

(10) Xu, X.; Cortie, M. B. Shape Change and Color Gamut in Gold Nanorods, Dumbbels, and Dog Bones. Adv. Funct. Mater. 2006, 16, 2170-2176.

(11) Gou, L.; Murphy, C. J. Solution-Phase Synthesis of Cu2O Nanocubes. Nano Lett. 2003, 3 (2), 231-234.

(12) Zhang, J.; Gao, Y.; Alvarez-Puebla, R. A.; Buriak, J. M.; Fenniri, $\mathrm{H}$. Synthesis and SERS Properties of Nanocrystalline Gold Octahedra Generated from Thermal Decomposition of HAuCl4 in Block Copolymer. Adv. Mater. 2006, 18, 3233-3237.

(13) Senthil Kumar, P.; Pastoriza-Santos, I.; Rodriguez-Gonzalez, B.; Javier Garcia de Abajo, F; Liz-Marzan, L. M High-yield Synthesis of Optical Response of Gold Nanostars. Nanotechnology 2008, 19, 015606.

(14) Wang, Z.; Bharathi, M. S.; Hariharaputran, R.; Xing, H.; Tang, L.; Li, J.; Zhang, Y.-W.; Lu, Yi. PH-dependent Evolution of Five-star Gold Nanostructures: An Experimental and Computational Study. ACS Nano 2013, 7, 2258-2265.
(15) Lee, J.-H.; Kamada, K.; Enomoto, N.; Hojo, J. Seeding Method for Three-dimensional Dendritic Growth of Gold Nanoparticles Stabilized by Hexatrimethylammonium Bromide. Chem. Lett. 2007, 36, 728-730.

(16) Ren, Y.; Xu, C.; Wu, M.; Niu, M.; Fang, Y. Controlled Synthesis of Golf Nanoflowers Assisted by Poly(vinyl pyrrolidone)-Sodium Dodecyl Sulfate Aggregations. Colloids Surf., A 2011, 380, 222-228.

(17) Huang, J.; Han, X.; Wang, D.; Liu, D.; You, T. Facile Synthesis of Dendritic Gold Nanostructures with Hyperbranched Architectures and their Electrocatalytic Activity toward Ethanol Oxidation. ACS Appl. Mater. Interfaces 2013, 5, 9148-9154.

(18) Hau, N. Y.; Yang, P.; Liu, C.; Wang, J.; Lee, P.-H.; Feng, S.-P. Aminosilane-Assisted Electrodeposition of Gold Nanodendrites and their Catalytic Properties. Sci. Rep. 2017, 7, 39839.

(19) Zhang, X.; Shi, F.; Yu, X.; Liu, H.; Fu, Y.; Wang, Z.; Jiang, L.; Li, $\mathrm{X}$. Polyelectrolyte Multilayer as Matrix for Electrochemical Deposition of Gold Clusters: toward Super hydrophobic Surface. J. Am. Chem. Soc. 2004, 126, 3064-3065.

(20) Tang, X.-L.; Jiang, P.; Ge, G.-L.; Tsuji, M.; Xie, S.-S.; Guo, Y.-J. Poly(N-vinyl-2 pyrrolidone) (PVP)-Capped Dendritic Gold Nanoparticles by One-step Hydrothermal Route and their High SERS Effect. Langmuir 2008, 24, 1763-1768.

(21) Jana, N. R.; Gearheart, L.; Murphy, C. J. Seed-Mediated Growth Approach for Shape controlled Synthesis of Spheroidal and Rod-like Gold Nanoparticles using a Surfactant Template. Adv. Mater. 2001, 13, 1389-1993.

(22) Pan, M.; Xing, S.; Sun, T.; Zhou, W.; Sindoro, M.; Teo, H. H.; Yan, Q.; Chen, H. 3D Dendritic Gold Nanostructures: Seeded Growth of a Multi-Generation Fractal Architecture. Chem. Commun. 2010, 46, $7112-7114$.

(23) Huang, D.; Bai, X.; Zheng, L. Ultrafast Preparation of Threedimensional Dendritic Gold Nanostructures in Aqueous Solution and their Applications in Catalysis and SERS. J. Phys. Chem. C 2011, 115, 14641-14647.

(24) Han, X.; Wang, D.; Huang, J.; Liu, D.; You, T. Ultrafast Growth of Dendritic Gold Nanostructures and their Applications in Methanol Electro-oxidation and SERS. J. Colloid Interface Sci. 2011, 354, 577584.

(25) Lv, Z.-Y.; Mei, L.-P.; Chen, W.-Y.; Feng, J.-J.; Chen, J.-Y.; Wang, A.-J. Shaped-controlled Electrosynthesis of Gold Nanodendrites for Highly Selective and Sensitive SERS Detection of Formaldehyde. Sens. Actuators, B 2014, 201, 92-99.

(26) Lv, Z.-Y.; Li, A.-Q.; Fei, Y.; Li, Z.; Chen, J.-R.; Wang, A.-J.; Feng, J.-J. Facile and Controlled Electrochemical Route to Three-dimensional Hierarchical Dendritic Gold Nanostructures. Electrochim. Acta 2013, 109, 136-144.

(27) Frens, G. Controlled Nucleation for the Regulation of the Particle Size in Monodisperse Gold Suspensions. Nature, Phys. Sci. 1973, 241, 20-22.

(28) Park, S.; Wang, J.-Y.; Kim, B.; Xu, J.; Russell, T. P. A Simple Route to Highly Oriented and Ordered Nanoporous Block Copolymer Templates. ACS Nano 2008, 2, 766-772.

(29) Park, S.; Wang, J.-Y.; Kim, B.; Russell, T. P. From Nanorings to Nanodots by Patterning with Block Copolymer. Nano Lett. 2008, 8, $1667-1672$.

(30) Burns, A.; Ow, H.; Wiesner, U. Fluorescent Core-shell Silica Nanoparticles: towards "Lab on a Particle" Architectures for Nanobiotechnology. Chem. Soc. Rev. 2006, 35, 1028-1042.

(31) Naik, A. K.; Hanay, M. S.; Hiebert, W. K.; Feng, X. L.; Roukes, M. L. Towards Single Molecule Nanomechanical Mass Spectrometry. Nat. Nanotechnol. 2009, 4, 445-450.

(32) Deo, R. P.; Lawrence, N. S.; Wang, J. Electrochemical Detection of Amino Acids at Carbon Nanotube and Nickel-carbon Nanotube Modified Electrodes. Analyst 2004, 129, 1076-1081.

(33) Coussot, G.; Perrin, C.; Moreau, T.; Dobrijevic, M.; Le Postollec, A.; Vandenabeele Trambouze, O. A Rapid and Reversible Colorimetric Assay for the Characterization of Aminated Solid Surfaces. Anal. Bioanal. Chem. 2011, 399, 1061-1069. 
(34) Dehdari Vais, R. D.; Sattarahmady, N.; Karimian, K.; Heli, H. Green Electrodeposition of Gold Hierarchical Dendrites of Pyramidal Nanoparticles and Determination of Azathioprine. Sens. Actuators, $B$ 2015, 215, 113-118.

(35) Li, F.; Han, X.; Liu, S. Development of an Electrochemical DNA Biosensor with a High Sensitivity of $\mathrm{fM}$ by Dendritic Gold Nanostructure Modified Electrode. Biosens. Bioelectron. 2011, 26, 2619-2625

(36) Adler, C.; Teleki, A.; Kuentz, M. Multifractal Characterization of Pharmaceutical Hot Melt Extrudates. Pharm. Res. 2017, 34, 321-332.

(37) Ji, X.; Song, X.; Li, J.; Bai, Y.; Yang, W.; Peng, X. Size Control of Gold Nanocrystals in Citrate Reduction: The Third Role of Citrate. J. Am. Chem. Soc. 2007, 129, 13939-19948.

(38) Krawiec, H.; Vignal, V.; Oltra, R. Use of the Electrochemical Microcell Technique and the SVET for Monitoring Pitting Corrosion at MnS Inclusions. Electrochem. Commun. 2004, 6, 655-660.

(39) Nishimura, S.; Mott, D.; Takagaki, A.; Maenosono, S.; Ebitani, K. Role of Base in the Formation of Silver Nanoparticles Synthesized Using Sodium Acrylate as a Dual Reducing and Encapsulating Agent. Phys. Chem. Chem. Phys. 2011, 13, 9335-9343.

(40) Makhsin, S. R.; Razak, K. A.; Noordin, R.; Zakaria, N. D.; Chun, T. S. The Effect of Size and Synthesis Methods of Gold Nanoparticleconjugated $\mathrm{M} \alpha \mathrm{HIgG} 4$ for use in an Immunochromatographic Strip Test to Detect Brugian Filariasis. Nanotechnology 2012, 23, 495719495732.

(41) Grassberger, P. Generalizations of the Hausdorff Dimension of Fractal Measures. Phys. Lett. A 1985, 107, 101-105.

(42) Thambi, V.; Kar, A.; Ghosh, P.; Paital, D.; Gautam, A. R. S.; Khatua, S. Synthesis of Complex Nanoparticle Geometries via PHControlled Overgrowth of Gold Nanorods. ACS Omega 2019, 4 (9), 13733-13739.

(43) Zhao, P.; Li, N.; Astruc, D. State of the Art in Gold Nanoparticle Synthesis. Coord. Chem. Rev. 2013, 257, 638-665.

(44) Lin, Z.-H.; Lin, M.-H.; Chang, H.-T. Facile Synthesis of Catalytically Active Platinum Nanosponges, Nanonetworks, and Nanodendrites. Chem. - Eur. J. 2009, 15, 4656-4662.

(45) Zhang, H.; Lu, Y.; Liu, H.; Fang, J. Controllable Synthesis of Three-dimensional Branched Gold Nanocrystals assisted by Cationic Surfactant Poly(diallyldimethylammonium) Chloride in Acidic Aqueous Solution. RSC Adv. 2014, 4, 36757-36764.

(46) Xie, J.; Zhang, Q.; Lee, J. Y.; Wang, D. I. The Synthesis of SERSactive Gold Nanoflowers Tags for in Vivo Applications. ACS Nano 2008, 2, 2473-2480.

(47) Xiao, J.; Qi, L. Surfactant-assisted, Shape-controlled Synthesis of Gold Nanocrystals. Nanoscale 2011, 3, 1383-1396.

(48) Xu, H.; Bjerneld, E. J.; Aizpurua, J.; Apell, P.; Gunnarsson, L.; Petronis, S.; Kasemo, B.; Larsson, C.; Höök, F.; Kall, M. Interparticle Coupling Effects in SERS. Proc. SPIE 2001, 4258, 35.

(49) Wang, Y.; Liu, J.; Zhao, X.; Yang, C.; Ozaki, Y.; Xu, Z.; Zhao, B.; Yu, Z. A Chiral Signal Amplified Sensor for Enantioselective Discrimination of Amino Acids Based on Charge Transfer-Induced SERS. Chem. Commun. 2019, 55, 9697.

(50) Mensch, C.; Johannessen, C. The influence of the amino acid side-chains on the Raman optical activity spectra of proteins. ChemPhysChem 2019, 20, 1-21.

(51) Zhang, Q.; Fu, M.; Lu, M.; Fan, X.; Wang, H.; Zhang, Y.; Wang, $\mathrm{H}$. Novel potential and current type chiral amino acids biosensor based on L/D- T handed double helix carbon nanotubes@polypyrrole@Au nanoparticles@L/ D-cysteine. Sens. Actuators, B 2019, 296, 126667.

(52) Zhang, L.; Liu, Z.; Xiong, C.; Zheng, L.; Ding, Y.; Lu, H.; Zhang, G.; Qiu, L. Selective recognition of Histidine enantiomers using novel molecularly $\mathrm{T}$ imprinted organic transistor sensor. Org. Electron. 2018, 61,254-260.

(53) Arnaboldi, S.; Magni, M.; Mussini, P. R. Review Article Enantioselective selectors for chiral electrochemistry and electroanalysis: Stereogenic elements and enantioselection performance. Curr. Opin. Electroche. 2018, 8, 60-72h.

(54) Hentschel, M.; Schäferling, M.; Duan, X.; Giessen, H.; Liu, N. Chiral plasmonics. Sci. Adv. 2017, 3, e1602735. 